\title{
Compression Field Analysis of \\ Fiber-Reinforced Concrete Based on Cracked Membrane Model
}

\author{
Journal Article \\ Author(s): \\ Kaufmann, Walter (D); Mata Falcón, Jaime (D); Amin, Ali \\ Publication date: \\ 2019-09 \\ Permanent link: \\ https://doi.org/10.3929/ethz-b-000365523
}

Rights / license:

Creative Commons Attribution-NonCommercial-NoDerivatives 4.0 International

Originally published in:

ACI Structural Journal 116(5), https://doi.org/10.14359/51716763 

MEMBRANE MODEL

\section{BIOGRAPHY}

Walter Kaufmann is Professor and Chair of Concrete Structures and Bridge Design at ETH Zurich, Switzerland. He has over 25 years of experience working both in academia and as a structural engineer. His research interests include the design and analysis of conventional, prestressed, digitally fabricated, and fiber-reinforced concrete structures.

Jaime Mata-Falcón is a Postdoctoral Researcher at ETH Zurich, Switzerland. He received his

Master's and PhD degrees from the Polytechnic University of Valencia, Spain. His research interests

11 include the design and analysis of conventionally and digitally fabricated concrete structures.

Ali Amin is a Lecturer in the School of Civil Engineering at The University of Sydney, Australia. He received his $\mathrm{BE}$ and $\mathrm{PhD}$ from UNSW Australia in 2011 and 2015, respectively. He is a member of the Concrete Institute of Australia. His research interests include the structural design and analysis of fiber reinforced and high performance concretes. the simplified Cracked Membrane Model considering rotating, stress-free cracks is extended to include the effect of fiber reinforcement. The key advantage of the proposed compression field approach is that it yields the most important factors for the design and analysis of fiber reinforced concrete (FRC) - that is, crack opening and spacing - directly. A solution procedure is developed herein for two practical design cases for webs of girders without conventional shear reinforcement. In both cases, the applied load can typically be increased after cracking even when using strain 
reinforced FRC panels satisfactorily but fails to capture failures governed by sliding of cracks in

27 elements containing high fiber dosages.

28 Keywords: fiber reinforced concrete; in-plane shear and normal forces; plane stress; compression field approaches; shear strength; load-deformation analysis.

\section{INTRODUCTION}

31 It is widely recognized in academia and practice that the addition of steel fibers to concrete may significantly increase the shear strength of reinforced concrete. In certain cases, steel fibers have the capacity to completely replace conventional shear ligature reinforcement ${ }^{1}$. This is particularly appealing from an economic and architectural perspective, as the replacement of manually placed steel bar reinforcement with an equivalent dosage of fiber reinforced concrete (FRC) would be extremely beneficial to a project's construction speed, and eliminating the installation of conventional reinforcement would facilitate the construction of free form, non-orthogonal beam and slab geometries, which may otherwise be difficult with conventional reinforcing bar layouts and formwork systems.

However, using practical and economical fiber dosages, FRC typically exhibits a softening response order to achieve a sufficient amount of ductility, which is required to enable the imposed actions to redistribute as the collapse load is approached. This is a prerequisite for the omission of restraint members. Design codes such as AS3600-2018 ${ }^{2}$ have imposed severe limits on the use of FRC for 
51 in tension, where the addition of moderate amounts of fibers may even have a detrimental effect on 52 the ductility of girders containing conventional longitudinal reinforcing steels ${ }^{3,4}$. However, it is less understandable for elements subjected to shear, where conventionally reinforced concrete girders, in compliance with international design codes, usually contain transverse reinforcement ratios in the order of about one quarter of the amount required to achieve a ductile behavior in tension (see References $\left.^{5,6}\right)$. In fact, many experimental campaigns ${ }^{7-11}$ have shown that this is sufficient to avoid premature, brittle shear failures, even if activating the shear resistance requires substantial stress redistribution in the web. Furthermore, several experimental studies on the shear behavior of FRC beams $^{12-15}$ indicate that brittle shear failures can be mitigated and transformed to ductile flexural failures by adding a sufficient dosage of steel fibers to the concrete, without providing additional conventional transverse stirrup reinforcement.

Indeed, several recently revised international codes of practice now contain provisions, which permit designers to rely on steel fibers in carrying a portion of the imposed one-way shear in structural concrete $^{2,16-18}$. However, the conditions for such applications are restrictive, typically limiting the use of steel fibers to resist relatively low shear forces (e.g. $30 \%$ of the total shear according to Reference ${ }^{16}$ ) and requiring uneconomically high minimum fiber contents (e.g. $\rho_{f, \min }=0.75 \%$ according to ACI-318 ${ }^{18}$ ) which may impede the workability of fresh concrete. Such severe restrictions for the use of steel fibers as the only mechanism in carrying shear in structural concrete are pertinent and should be respected, as long as existing models for the global shear strength of fiber reinforced concrete members are semi-empirical. Generally, these design approaches assume that the total shear $V_{R}$, is partially resisted by a component taken by the plain concrete, $V_{R c}$, a component taken by the fibers, $V_{R f}$, and, where applicable, a component resisted by the transverse reinforcement, $V_{R s}$, resulting in a total resistance $V_{R}=V_{R c}+V_{R f}+V_{R s}$. The $V_{R s}$ component is usually obtained from a truss model and the components $V_{R c}$ and $V_{R f}$ are typically calibrated on tests. A first step in the direction of a mechanically based model for the shear strength of FRC was made by the alternative approach 
$V_{R f}$ that essentially corresponds to a compression field approach. However, the inclination of the compression field and the crack width required in determining the effective fiber bridging stresses are evaluated using semi-empirical equations. Furthermore, the empirical concrete contribution, $V_{R c}$, which is somewhat related to the shear at the commencement of diagonal cracking, is still added to obtain the global shear strength. This is in contrast to well-established approaches for conventionally reinforced structural concrete, where if the minimum shear reinforcement discussed above is provided, a safe and economical design is possible using a simple variable angle truss model approach, based on the lower bound theorem of the theory of plasticity ${ }^{19,22,23}$, without the need for empirical concrete contributions. In order to fully exploit the potential of using steel fibers as shear reinforcement, mechanically consistent models for the design and analysis of FRC in shear must be developed.

(1)

\section{RESEARCH SIGNIFICANCE}

It is well established that the addition of fibers to concrete increases the shear strength of a reinforced concrete member. Available models describing the behavior of fiber reinforced concrete (FRC) in shear are, however, founded on semi-empirical rationale. This paper presents a mechanically consistent rotating crack model to describe the behavior of FRC elements in plane stress. The model is based on the Cracked Membrane Model $^{23,24}$, a compression field approach for conventionally reinforced concrete, extended herein to account for fiber reinforcement. Through this study, improved methods of analysis of FRC members subjected to shear can be rationally achieved.

\section{COMPRESSION FIELD APPROACHES}

\section{Compression field approaches for conventionally reinforced concrete elements}

The load-deformation behavior of diagonally cracked reinforced concrete elements can be readily analyzed using compression-field approaches. These approaches were developed several decades $\operatorname{ago}^{25,26}$, and systematically satisfy equilibrium conditions and compatibility requirements. The basic concepts of such models are illustrated in Fig. 1 for the special case of orthogonal reinforcement, 
102 whereby the horizontal and vertical reinforcement are assumed to coincide with the $x$ - and $z$ 103 directions, respectively.

104 Consider the element shown in Fig. 1a. Noting that the sum of forces in the concrete and 105 reinforcement must correspond to the applied loads (Fig. 1d), the following two equivalent sets of 106 equilibrium conditions are obtained

$$
\begin{array}{lll}
\sigma_{x}=\sigma_{c x}+\sigma_{s x}=\sigma_{c 3} \cos ^{2} \theta+\sigma_{c 1} \sin ^{2} \theta+\rho_{x} \sigma_{s x} & \rho_{x} \sigma_{s x}=\sigma_{x}+\tau_{z x} \cot \theta-\sigma_{c 1} \\
\sigma_{z}=\sigma_{c z}+\sigma_{s z}=\sigma_{c 3} \sin ^{2} \theta+\sigma_{c 1} \cos ^{2} \theta+\rho_{z} \sigma_{s z} & \text { or } & \rho_{z} \sigma_{s z}=\sigma_{z}+\tau_{z x} \tan \theta-\sigma_{c 1} \\
\tau_{z x}=\tau_{c z x}+\tau_{s z x}=\left(\sigma_{c 1}-\sigma_{c 3}\right) \sin \theta \cos \theta & \sigma_{c 3}=-\tau_{z x}(\tan \theta+\cot \theta)+\sigma_{c 1}
\end{array}
$$

108 if the reinforcing bars are assumed to only carry uniaxial stresses along their longitudinal axis, i.e.

109 neglecting dowel action such that $\tau_{s z x}=0$. In Fig. 1d, $\rho_{x}$ and $\rho_{z}$ are the geometric reinforcement

110 ratios in the $x$ - and $z$-directions, respectively, $\sigma_{c}$ and $\sigma_{s}$ are the stresses in the concrete and 111 reinforcement, respectively and $\theta$ is the principal compressive stress and strain direction.

112 Compatibility requires that the strains (Fig. 1b) are related through

$113 \quad \cot ^{2} \theta=\frac{\varepsilon_{z}-\varepsilon_{3}}{\varepsilon_{x}-\varepsilon_{3}}=\frac{\varepsilon_{1}-\varepsilon_{x}}{\varepsilon_{x}-\varepsilon_{3}}=\frac{\varepsilon_{z}-\varepsilon_{3}}{\varepsilon_{1}-\varepsilon_{z}}$

114 i.e., the state of strain is fully determined by three independent unknowns. Expressing the concrete 115 stresses $\left(\sigma_{c 1}, \sigma_{c 3}\right)$ and the stresses in the reinforcement $\left(\sigma_{s x}, \sigma_{s z}\right)$ in terms of any 3 non-collinear 116 strains, e.g. $\left(\varepsilon_{x}, \varepsilon_{z}, \varepsilon_{3}\right)$, and using constitutive relationships relating stresses and strains of concrete 117 and reinforcement, respectively, the states of stress and strain can be determined iteratively by solving 118 the 3 equations in Eqs. (1) for the 3 unknown strains.

119 The Equations presented in Eqs. (1) may be simplified by neglecting the tensile stresses in the 120 concrete (i.e. $\sigma_{c 1}=0$, refer to Fig. 1c), as typically assumed in design ${ }^{23}$. For linear elastic behavior 121 for the reinforcement and concrete, with $n=E_{s} / E_{c}$, Baumann's closed-form equation for the 122 principal compressive stress and strain direction is obtained ${ }^{27}$ :

$$
\tan ^{2} \theta \rho_{x}\left(1+n \rho_{z}\right)+\tan \theta \rho_{x} \frac{\sigma_{z}}{\tau_{x z}}=\cot ^{2} \theta \rho_{z}\left(1+n \rho_{x}\right)+\cot \theta \rho_{z} \frac{\sigma_{x}}{\tau_{x z}}
$$


124 Having determined the principal compressive stress and strain direction $\theta$ from Eq. (3), obtaining the response (strains for any given applied stresses) by inserting $\theta$ in Eqs. (1) is straightforward.

126 Neglecting the tensile strength of the concrete, $f_{c t}$, in any direction corresponds to the assumption of 127 fictitious, rotating, stress-free cracks which open orthogonally, and hence, the principal compressive 128 directions of average strains $\theta_{\varepsilon}$ and concrete stresses $\theta_{\sigma}$ coincide with the direction of the fictitious 129 cracks $\theta_{r}\left(\theta_{r}=\theta_{\varepsilon}=\theta_{\sigma}=\theta\right)$, refer to Fig. 1. Predictions obtained using this type of classical compression 130 field approach - even if using nonlinear constitutive relationships for concrete and reinforcement ${ }^{28}$ 131 tend to overestimate the observed deformations since rotating cracks are considered and tension 132 stiffening effects are neglected. Furthermore, they typically overestimate the ultimate load unless 133 compression softening of the concrete is accounted for ${ }^{23}$.

134 Vecchio and Collins proposed the Modified Compression Field Theory (MCFT) ${ }^{29}$ to overcome these weaknesses. In the MCFT, tension stiffening is implicitly taken into account by formulating equilibrium in terms of average stresses between the cracks, including average tensile stresses in the concrete (Fig. 1d). However, by treating the assumed average tensile stresses in the concrete as a material property, depending only on the principal tensile strain, the respective empirical constitutive equations disregard the fact that tension stiffening strongly depends on the rebar diameter and the steel reinforcement ratios $^{30}$. Consequently, such an approach is unable to yield direct information on 141 the maximum stresses at the cracks nor on crack spacings or crack widths. The same remark applies 142 to other models formulating equilibrium in terms of average stresses between cracks ${ }^{31,32}$.

143 Extending this methodology for FRC is not entirely appropriate as the most important property when 144 considering the design of a structural member manufactured with FRC is its post cracking, or residual, tensile strength. The strength that is offered by the fibers across a crack is dependent on the width of 146 the crack. Hence for a reliable analysis of FRC elements, information on the crack opening must be established. This is why compression field models formulating equilibrium in terms of stresses at the cracks, which can yield direct information on crack spacing and openings, are much better suited for the analysis of FRC elements in shear. One such model is the Cracked Membrane Model (CMM) ${ }^{23,24}$. 
In its general formulation (CMM-F), this model allows treating cracks as fixed and interlocked rather

151 than as rotating and stress-free while accounting for shear and normal stresses on the crack faces as 152 well as bond stresses transferred between the concrete and steel reinforcement. Equilibrium 153 conditions are expressed in terms of stresses at the cracks (see Fig. 2), and crack spacings and tensile 154 stresses between the cracks are determined from basic mechanical principles adopted from the 155 Tension Chord Model (TCM) $)^{5}$. However, calculations using this general model are tedious, and the 156 assumption of interlocked cracks with a fixed direction is of limited use for design purposes, since 157 this is equivalent to allowing substantial tensile stresses to develop in the concrete between the cracks. 158 Therefore, the simplified version of the model considering rotating, stress-free cracks, the CMM-R, 159 is considered in the following ${ }^{23,24}$. This model has been successfully implemented in FE-codes by 160 several researchers ${ }^{33-35}$, including a generalization to the analysis of shell elements using a sandwich 161 model approach ${ }^{36-38}$.

162 In the CMM-R, contrary to the CMM-F, cracks are assumed to be stress free and open orthogonally. 163 These two assumptions greatly simplify the calculations without losing the direct information on the 164 local stresses at the cracks and crack openings, since equilibrium conditions are expressed in terms 165 of stresses at the cracks. In particular, Eqs. (1) can be simplified neglecting the tensile stresses in the 166 concrete at the cracks (i.e. setting $\sigma_{c 1}=0$, refer to Fig. $1 \mathrm{c}$ ) and remain valid if stresses in the concrete 167 and reinforcement at the cracks, as well as $\theta_{r}=\theta$ are inserted, and a closed form solution for the 168 diagonal crack spacing, $s_{r}$, can be established based on the theoretical maximum crack spacings for 169 uniaxial tension in the reinforcement directions, $s_{r x 0}$ and $s_{r z 0}$, respectively ${ }^{23,24}$. The latter are obtained 170 observing that while $\sigma_{c 1}=0$ at the cracks, tensile stresses are transferred to the concrete between the 171 cracks by bond shear stresses, and that the tensile stresses in the concrete cannot exceed $f_{c t}$ midway 172 between two cracks. Using the $\mathrm{TCM}^{5}$, which assumes constant rigid-plastic bond stresses (i.e. 173 independent of the slip) prior to yielding of the reinforcement, the maximum theoretical crack 174 spacings for uniaxial tension are given by 


$$
s_{r x 0}=\frac{\emptyset_{x} f_{c t}\left(1-\rho_{x}\right)}{2 \tau_{b 0} \rho_{x}} \approx \frac{\emptyset_{x} f_{c t}}{2 \tau_{b 0} \rho_{x}}=\frac{\emptyset_{x}}{4 \rho_{x}}, s_{r z 0}=\frac{\emptyset_{z} f_{c t}\left(1-\rho_{z}\right)}{2 \tau_{b 0} \rho_{z}} \approx \frac{\emptyset_{z}}{4 \rho_{z}} \quad\left(\tau_{b 0}=2 f_{c t}\right)
$$

where $\varnothing_{x}$ and $\varnothing_{z}$ are the bar diameters in the $x$ - and $z$-directions, respectively, $\tau_{b 0}=2 f_{c t}=0.6 f_{c}^{2 / 3}$ is the bond shear stress for elastic reinforcement according to the TCM, with $f_{c}$ being the concrete cylinder strength in $\mathrm{MPa}$ units. Note that the minimum theoretical crack spacing is half the corresponding maximum crack spacing, since at the limit, a new crack may form when $\sigma_{c 1}=f_{c t}$ is attained midway between two cracks. This uncertainty cannot be avoided, even with more realistic, complex bond shear stress-slip relationships, which justifies the use of a simplified, yet mechanically consistent model like the $\mathrm{TCM}^{5}$. In order to determine the crack spacing in biaxially reinforced elements, the stresses in the concrete between the cracks can be determined by superimposing the concrete stresses at the crack with the stresses transferred to the concrete between the cracks by bond shear stresses from both sets of orthogonally placed reinforcing bars. Noting that the crack spacings are geometrically related through $s_{r}=s_{r x} \sin \theta=s_{r z} \cos \theta$ (see Fig. 2a), and that just as for uniaxial tension, the maximum diagonal crack spacing $s_{r 0}$ is attained when $\sigma_{c 1}=f_{c t}$ occurs at the center between two cracks, $s_{r 0}$ can be determined analytically ${ }^{23,24}$. A good upper bound approximation for $S_{r 0}$ is given by

$$
S_{r 0}=\frac{1}{\frac{\sin \theta}{s_{r x 0}}+\frac{\cos \theta}{S_{r z 0}}}
$$

Eq. (5) is the same equation postulated by Vecchio and Collins ${ }^{29}$. Like in uniaxial tension ${ }^{5,6}$, the diagonal crack spacing may also vary by a factor of two, i.e. $s_{r}=\lambda s_{r 0}$, with $\lambda=0.5 \ldots 1.0^{23,24}$. The crack opening, $w_{r}$, can be determined from the principal tensile strain, $\varepsilon_{1}$, and the diagonal crack spacing $s_{r}=\lambda s_{r 0}$, i.e.

$$
w_{r}=s_{r}\left(\varepsilon_{1}-\varepsilon_{c 1}\right) \approx s_{r} \varepsilon_{1}=\lambda s_{r 0} \varepsilon_{1}
$$


Eq. (6) is simplified by neglecting the tensile strains within the concrete between the cracks, $\varepsilon_{c 1}$, without significantly affecting accuracy, since typically, $\varepsilon_{c 1} \ll \varepsilon_{1}$.

Knowing the crack spacing (or rather, selecting a value between its theoretical upper and lower boundaries), the CMM-R analysis can be carried out as outlined above for classic compression field models, i.e. solving the Eqs. (1) (with $\sigma_{c 1}=0$ ) to obtain the state of strain ( 3 unknowns) for any given set of applied stresses. However, constitutive relationships for the concrete and the reinforcement expressing the (maximum) stresses at the cracks in terms of average strains are required. The TCM allows for determining these relationships consistently as a function of the crack spacing ${ }^{5}$, with closed-form analytical solutions e.g. when using a bilinear stress-strain relationship for the bare bar reinforcement. For linear elastic reinforcement, a closed form solution for the crack inclination $\theta_{r}$, similar to Eq. (3) but accounting for tension stiffening in a consistent manner, can be derived, and is a useful tool for verifications of the serviceability limit state, particularly for crack widths ${ }^{39}$. For more details, the reader is referred to References ${ }^{23,24}$.

\section{Compression field approach for FRC elements}

Adapting the CMM-R to account for fiber reinforcement (CMM-Rf) is straightforward, since

211 equilibrium is formulated at the cracks and fiber stresses at cracks can be determined from the crack

212 kinematics that are directly obtained from the model. Hence, equilibrium can simply be expressed 213 using Eqs. (1) (Fig. 1d), and setting $\sigma_{c 1}=\sigma_{c f}$, where $\sigma_{c f}$ is the effective (residual) fiber stresses at 214 the cracks. These stresses act perpendicularly to the crack face and hence, in the direction of the 215 principal concrete tensile stresses. The residual stresses provided by the fibers are dependent on the 216 crack opening, i.e. $\sigma_{c 1}=\sigma_{c f}(u)$, where $u=w_{r}$ and can be obtained from Eq. (6).

217 However, the crack spacings (refer to Eq. (4)) need to be adapted to account for the fiber bridging 218 stresses. As outlined above for conventional reinforced concrete, moving away from a crack along a 219 reinforcing bar, the tensile stresses in the surrounding concrete will gradually build up, as a result of 220 bond shear stresses transferred from the reinforcement, to a value up to $f_{c t}$. This distance is shorter in 
FRC than in concrete without fibers since in addition to bond, the fiber stresses $\sigma_{c 1}=\sigma_{c f}$ at the crack are transmitted to the concrete over the fiber embedment length $l_{b f} \leq l_{f} / 2$. Using the same assumptions as in the TCM, the following crack spacings for uniaxial tension in the reinforcement directions, accounting for additional fiber reinforcement, result ${ }^{3}$ :

$$
s_{r x f 0}=\frac{\emptyset_{x}}{4 \rho_{x}}\left(1-\frac{\sigma_{c f}}{f_{c t}}\right), s_{r z f 0}=\frac{\emptyset_{z}}{4 \rho_{z}}\left(1-\frac{\sigma_{c f}}{f_{c t}}\right) \quad\left(\tau_{b 0}=2 f_{c t}\right)
$$

Using Eqs. (7), the maximum diagonal crack spacing can be determined as for conventionally reinforced panels, again with $s_{r f}=\lambda s_{r f 0}(\lambda=0.5 \ldots 1.0)^{23,24}$. The diagonal crack spacing $s_{r f}=s_{r z f} \sin \theta=s_{r x f} \cos \theta$ accounting for biaxial reinforcement and fibers, can be determined based on the theoretical maximum diagonal crack spacing, $s_{r f 0}$, as follows:

$$
S_{r f 0}=\frac{1}{\frac{\sin \theta}{s_{r x f 0}}+\frac{\cos \theta}{s_{r z f 0}}}=\frac{1-\sigma_{c f} / f_{c t}}{\frac{\sin \theta}{s_{r x 0}}+\frac{\cos \theta}{s_{r z 0}}}, \quad S_{r f}=(0.5 \ldots 1.0) s_{r f 0} \geq l_{f}
$$

231 where $\theta$ is the principal compressive stress direction at the onset of initial cracking.

232 Note that for high fiber dosages, Eqs. (7) can yield very small or even negative crack spacings (for $233 \sigma_{c f}>f_{c t}$ ); however, this is physically impossible since for small crack spacings, these high fiber stresses cannot be activated. By this, an imposed lower bound limit for the crack spacing is taken as 235 the length of the fiber (i.e. $s_{r f} \geq l_{f}$ ) as indicated in Eq. (8). Since the crack opening is typically small 236 during the crack formation process, a reasonable approximation of the crack spacing is obtained by 237 setting $\sigma_{c f} \approx \sigma_{c f 0}$ in Eqs. (7) and (8), where $\sigma_{c f 0}$ denotes the fiber effectiveness, corresponding to 238 the maximum value of residual fiber stresses at small crack openings as further outlined below (refer 239 to Eq. (11)).

240 For members without conventional reinforcement in either direction, Eq. (8) cannot be used. Rather, 241 for members with high fiber dosages, the crack spacing will be in the order of $s_{r f} \approx l_{f}$, and for low 242 fiber dosages, localized cracking is expected to occur unless the crack spacing in either direction is 
governed by adjacent elements, such as the chords in the case of the web of a girder. In the latter case,

244 the diagonal crack spacing in the web can be estimated geometrically, using the crack spacing $S_{r x, T C}$

245 in the tension chord:

$$
S_{r f}=s_{r x, T C} \sin \theta
$$

247 Knowing the crack spacing, the value of $\sigma_{c f}$ can be determined for a given state of strain (and hence 248 crack opening) using Eq. (6) and any suitable FRC material constitutive stress vs crack opening 249 relationship. In this paper, the simple mechanical model proposed by Pfyl ${ }^{3,40}$, illustrated in Fig. 3, is 250 adopted to estimate the residual characteristics of the FRC for the sake of simplicity. It is 251 acknowledged that more accurate expressions for the residual capacity of FRC may be obtained using 252 fiber stress vs crack opening characteristics derived directly from standard material tests on the actual 253 FRC used ${ }^{41}$, or through the use of more refined/sophisticated constitutive models that are available in 254 the literature ${ }^{42,43}$. Also, better predictions are likely to be obtained using statistical models to predict material parameters; however, this is beyond the scope of this paper.

256 While Pfyl's model considers fiber activation followed by a pull-out phase, only the latter is 257 considered in the following for simplicity (Fig. 3b). Hence, fiber stresses amount to

$$
\frac{\sigma_{c f}}{\sigma_{c f 0}}=\left(1-\frac{2 u}{l_{f}}\right)^{2} \quad\left(u \leq \frac{l_{f}}{2}\right)
$$

259 In the derivation of Eq. (10), fiber snubbing effects ${ }^{43}$ were neglected. The term $\sigma_{c f 0}$ denotes the fiber 260 effectiveness of the FRC, which can be expressed as

$$
\sigma_{c f 0}=K_{f} \frac{\rho_{f} \tau_{b f} l_{f}}{d_{f}}
$$

262 if the pullout resistance of the individual fibers is assumed to be independent of their inclination $\theta_{f}$ with respect to the outer normal to the crack surface. This assumption can be justified if fibers oriented 264 close to the crack plane (e.g. $\theta_{f}>\pi / 3$ as proposed by Foster ${ }^{44}$ ) are considered ineffective, as 265 assumed in the following. In Eq. (11), $\rho_{f}$ is the total volumetric fiber content, $K_{f}$ is a fiber 
orientation factor explained in the Appendix, and $\tau_{b f}$ is the average bond stress between the fibers and surrounding matrix along the shorter embedded length, which accounts for stress transfer between the fibers and the matrix by anchorage provided by end hooks, taken as $\tau_{b f}=2 f_{c t}=0.6 f_{c}^{2 / 3}$ (in $\mathrm{MPa}$ units).

270 In the discussion above a fundamental assumption is made on the failure mechanism of FRC in that the fibers pull-out of the matrix. If the axial stresses developed within the fibers exceeded the ultimate tensile strength of the fibers, $f_{t f}$, the fibers would fracture before being pulled out. Pfyl's model above can be extended for the case of fiber fracture, noting that fibers longer than

$$
l_{f b u}=\frac{f_{t f} d_{f}}{4 \tau_{b f}}
$$

would fracture before completely pulling out. However, the fiber geometry $\left(l_{f}, d_{f}\right)$ and properties are usually tuned to avoid this behavior. Therefore, fiber fracture is not considered in the development of the model.

Furthermore, it has been observed in tests on FRC members where single dominant/localized cracks form that the number of fibers bridging failure surfaces are generally lower than the total expected number of fibers ${ }^{41}$. It is thought that the crack path follows the easiest propagation route through the FRC matrix and often propagates through the inherent flaws of the concrete (such as pores) and near the end or around individual fibers. In shear critical FRC beams, Amin and Foster ${ }^{45}$ included a fiber dispersion factor of 0.82 which is applied to the average residual tension that is offered by the fibers to account for these observations. For FRC members containing steel rebar where many cracks are expected to form, it may be argued that the initial cracks may contain, on average, fewer fibers than theoretically expected. However, after first cracking, the location of the subsequent cracks depends more-so on the development of bond between the FRC matrix and steel rebar than the presence of the fibers. Assuming many cracks smeared along the element, and large crack surfaces, the influence of those few initial cracks with statistically fewer fibers becomes negligible to the overall response of 
the element. Note that it has also been observed in tension tie tests that one of these initial cracks is more likely to develop into the failure surface of the member, however these failure surfaces tend to localize well after peak load has been attained ${ }^{46,47}$. The CMM-Rf analysis including fibers can be carried out just as outlined above for the CMM-R without fibers, but solving Eq. (1) with $\sigma_{c 1}=\sigma_{c f}(u)$ instead with $\sigma_{c 1}=0$ to obtain the state of strain (3 unknowns) for a given set of applied stresses, where the crack opening $u=w_{r}$ can be determined from Eq. (6), using the crack spacing given by Eq. (8).

\section{Simplified compression field approach for FRC webs}

298 For elements without vertical reinforcement nor vertically applied stresses, as is the case for the webs 299 of girders without conventional shear stirrup reinforcement, the compression field analysis presented 300 above can be simplified. Using Eqs. (1) with $\sigma_{c 1}=\sigma_{c f}$ and setting $\rho_{z}=\sigma_{z}=0$, one obtains (Fig. 4c)

$$
\begin{aligned}
& \rho_{x} \sigma_{s x}-\sigma_{x}=\tau_{z x} \cot \theta-\sigma_{c f}=\tau_{z x}\left(\frac{\tau_{z x}}{\sigma_{c f}}-\frac{\sigma_{c f}}{\tau_{z x}}\right)=\frac{\tau_{z x}{ }^{2}}{\sigma_{c f}}-\sigma_{c f} \\
& \tan \theta=\frac{\sigma_{c f}}{\tau_{z x}} \\
& \sigma_{c 3}=-\frac{\tau_{z x}{ }^{2}}{\sigma_{c f}}
\end{aligned}
$$

302 Knowing $\sigma_{c f}$, the state of stress at the cracks for any applied stresses $\left(\sigma_{x}, \tau_{z x}\right)$ is thus uniquely determined by equilibrium alone. However, $\sigma_{c f}$ is a function of the crack opening, which in turn is dependent on the principal tensile strain (see Eq. (6)). Rather than using the general solution procedure, a more direct way consists of: (i) assuming a value of $\sigma_{c f}$; (ii) determining the corresponding values of $\varepsilon_{x}, \varepsilon_{3}$ and $\theta$ from Eqs. (13), using the constitutive relationships of concrete and longitudinal reinforcement; (iii) determining the principal tensile strain using the compatibility condition Eq. (2), i.e. $\varepsilon_{1}=\varepsilon_{x}+\left(\varepsilon_{x}-\varepsilon_{3}\right) \cot ^{2} \theta$; (iv) calculating the resulting crack opening using Eq. (6); (v) determining the fiber stress corresponding to the obtained crack opening 
310 from Eq. (10); and (vi) iterating through steps (i)-(v) until the resulting fiber effective stress converges

311 with the initially assumed value.

312 Assuming linear elastic behavior of the concrete in compression and, where applicable, for the

313 longitudinal reinforcement in tension, further simplifications are possible. This is outlined below for 314 two cases of practical interest, representing possible situations in the webs of girders.

315 Consider first a uniaxially reinforced FRC element loaded in pure shear, i.e. $\rho_{z}=0$ and $\sigma_{x}=\sigma_{z}=0$.

316 Using the equilibrium conditions, Eqs. (13), one attains

$$
\varepsilon_{3}=\varepsilon_{c 3}-\frac{n \tau_{z x}{ }^{2}}{\sigma_{c f} E_{s}}, \quad \varepsilon_{x}=\frac{\tau_{z x}}{\rho_{x} E_{s}}\left(\frac{\tau_{z x}}{\sigma_{c f}}-\frac{\sigma_{c f}}{\tau_{z x}}\right)
$$

318 and inserting Eqs. (14) into the compatibility condition given by Eq. (2), i.e. $\varepsilon_{1}=\varepsilon_{x}+\left(\varepsilon_{x}-\varepsilon_{3}\right) \cot ^{2} \theta$,

319 the principal tensile strain amounts to

$$
\varepsilon_{1}=\frac{\tau_{z x}^{2}}{\rho_{x} E_{s} \sigma_{c f}}\left(\frac{\tau_{z x}^{2}}{\sigma_{c f}^{2}}\left(1+n \rho_{x}\right)-\frac{\sigma_{c f}^{2}}{\tau_{z x}^{2}}\right)
$$

321 Hence, the crack opening $w_{r}=s_{r} \varepsilon_{1}$ (see Eq. (6)) can be expressed in a closed form, and the states of stress and strain are found by simply solving the equation

$$
\sigma_{c f}\left(S_{r f} \cdot \frac{\tau_{z x}{ }^{2}}{\rho_{x} E_{s} \sigma_{c f i}}\left(\frac{\tau_{z x}^{2}}{\sigma_{c f i}{ }^{2}}\left(1+n \rho_{x}\right)-\frac{\sigma_{c f i}{ }^{2}}{\tau_{z x}{ }^{2}}\right)\right)=\sigma_{c f i}
$$

324 for an initially assumed value $\sigma_{c f i}$ of the fiber stress, using $\sigma_{c f}(u)$ defined by Eq. (10) (or any other, 325 more refined FRC constitutive model $^{42,43}$ ).

326 Consider next an element with $\rho_{x}=\rho_{z}=0$ of the web of a girder with stiff chords, whose strains are 327 typically dominated by bending moments, but generally also depend on the applied shear stresses, $328 \varepsilon_{x}=g\left(\tau_{z x}\right)$. The equilibrium conditions, Eqs. (13), in this case yield the strains

$$
\varepsilon_{3}=\varepsilon_{c 3}-\frac{n \cdot \tau_{z x}{ }^{2}}{\sigma_{c f} E_{s}}, \quad \varepsilon_{x}=g\left(\tau_{z x}\right)
$$




$$
\varepsilon_{1}=g\left(\tau_{z x}\right)\left(1+\frac{\tau_{z x}^{2}}{\sigma_{c f}^{2}}\right)+\frac{n \tau_{z x}^{4}}{E_{s} \sigma_{c f}^{3}}
$$

333 The crack opening $w_{r}=s_{r} \varepsilon_{1}$ (see Eq. (6)) can again be expressed in closed form, and the states of

334 stress and strain are determined by solving the equation

$$
\sigma_{c f}\left(S_{r f} \cdot\left(g\left(\tau_{z x}\right)\left(1+\frac{\tau_{z x}^{2}}{\sigma_{c f i}^{2}}\right)+\frac{n \tau_{z x}{ }^{2}}{E_{s} \sigma_{c f i}{ }^{3}}\right)\right)=\sigma_{c f i}
$$

336 for an initially assumed value $\sigma_{c f i}$, as above.

\section{DISCUSSION}

338 Figures 5 and 6 present the results of sample compression field analyses for the two special cases 339 discussed above, i.e. a uniaxially reinforced element (Fig. 5) and a FRC element without any conventional reinforcement, but subjected to imposed horizontal strains (Fig. 6), respectively. Two sets of calculations, both considering elastic behavior of the reinforcement, were carried out for each case, i.e. Figs. 5 and 6, considering (i) linear elastic behavior of the concrete, i.e. simply solving Eqs. (16) and (19), respectively, with $n=E_{s} / E_{c}=6$ (dashed lines), and (ii) following the simplified approach for FRC webs outlined in the previous section, using the following parabolic stress-strain relationship accounting for compression softening for the concrete (solid lines) ${ }^{23,24}$ :

$$
\sigma_{c 3}=-\left(\frac{2 \varepsilon_{c 3}}{\varepsilon_{c 0}}-\left(\frac{\varepsilon_{c 3}}{\varepsilon_{c 0}}\right)^{2}\right) \frac{f_{c}^{2 / 3}}{0.4+30 \varepsilon_{1}} \text { i.e. } \varepsilon_{c 3}=\varepsilon_{c 0}\left(1-\sqrt{1+\frac{\sigma_{c 3}}{f_{c}^{2 / 3}}\left(0.4+30 \varepsilon_{1}\right)}\right)
$$

In Eq. (20) $f_{c}$ is the concrete cylinder strength in MPa and $\varepsilon_{c 0}$ is the strain corresponding to the peak compressive stress $f_{\text {cred }}=f_{c}^{2 / 3} /\left(0.4+30 \varepsilon_{1}\right)$, with $\varepsilon_{c 3} \geq \varepsilon_{c 0} \approx-0.002$. The behavior is analyzed for a fiber effectiveness equivalent to $\sigma_{c f 0}=2.0 \mathrm{MPa}(0.29 \mathrm{ksi})$, for both the maximum, as well as the minimum theoretically predicted crack spacing, i.e. $\lambda=1.0$ and $\lambda=0.5$, respectively, to study the

351 influence on the response. Furthermore, it is assumed that the fiber geometry and matrix strength are 352 tuned such that ruptures of the fibers do not occur. The considered fiber effectiveness translates to a 
steel fiber dosage of approximately $40 \ldots 60 \mathrm{~kg} / \mathrm{m}^{3}\left(2.5 \ldots 3.8 \mathrm{lb} / \mathrm{ft}^{3}\right)\left(\rho_{f}=0.50-0.75 \%\right.$ by volume $)$ depending on the fiber orientation and the specific properties of the matrix and fibers).

The response of the uniaxially reinforced FRC element in pure shear, $\sigma_{x}=0$, is presented in Fig. 5, for a longitudinal reinforcement ratio of $\rho_{x}=1.5 \%$. The material parameters used in the analyses are indicated in the Figure. It can be seen that as predicted by the second equation in Eq. (13), the principal compressive stress direction rotates towards the horizontal $x$-axis with increasing shear stresses $\tau_{z x}$, and that $\cot \theta$ increases almost proportionally with $\tau_{z x}$ as long as the decrease in fiber stresses $\sigma_{c 1}=\sigma_{c f}$ due to crack opening $u$ is moderate. In the case of linear elastic concrete behavior (dashed lines), maximum loads of $\tau_{z x u} / \sigma_{c f 0}=1.63$ and $\tau_{z x u} / \sigma_{c f 0}=1.93$ are predicted for $\lambda=1.0$ and $\lambda=0.5$, respectively, with strains in the longitudinal reinforcement reaching $1.77 \cdot 10^{-3}$ and $2.81 \cdot 10^{-3}$. Hence, in this case, depending on the yield strength of the reinforcement, yielding of the reinforcement would govern failure, as indicated by the intersections of the vertical dotted line and model resultants shown in Figs. 5a and 5b for a yield strength of $500 \mathrm{MPa}(72.5 \mathrm{ksi})$. Note that while in an orthogonally reinforced panel, a load increase is possible after yielding of the reinforcement in one direction (accompanied by higher steel stresses in the other reinforcement direction), such a redistribution is not possible in a uniaxially reinforced FRC panel due to the strain-softening characteristics of the FRC. If the yield strength of the reinforcement is sufficiently high, fiber softening would be the governing mode of failure: as the tensile strains, $\varepsilon_{1}=\varepsilon_{x}+\left(\varepsilon_{x}-\varepsilon_{3}\right) \cot ^{2} \theta$, increase essentially in proportion with $\cot ^{2} \theta$ and hence, with $\tau_{z x}^{2}$, see the second equation in Eq. (13) , these increasing strains lead to progressively larger crack openings and consequently the ability of the fibers to transmit tension across cracks is reduced, which in turn requires flatter inclinations until the point where equilibrium cannot be satisfied. For nonlinear concrete behavior (solid lines), maximum loads of $\tau_{z x u} / \sigma_{c f 0}=1.58$ and $\tau_{z x u} / \sigma_{c f 0}=1.82$ are predicted for $\lambda=1.0$ and $\lambda=0.5$, respectively, with corresponding strains at the peak load in the longitudinal reinforcement reaching 
$1.56 \cdot 10^{-3}$ and $2.19 \cdot 10^{-3}$. Hence, in this case, reinforcement yielding will not govern unless low strength reinforcement is used and failure occurs when equilibrium cannot be satisfied due to the combined effect of tensile softening of the fiber stresses, as outlined for the linear case, and compression softening of the concrete. The latter is very pronounced, since the compressive strength decreases hyperbolically with increasing tensile strains, $\varepsilon_{1}$, see Eq. (20) that in turn grow essentially in proportion with $\cot ^{2} \theta$ and $\tau_{z x}^{2}$, see above, just like the concrete compressive stresses, see the third equation in Eq. (13).

Noting that cracking under pure shear is expected to occur at $\tau_{z x r}=f_{c t} \approx 0.3 f_{c}^{2 / 3}=3.5 \mathrm{MPa}(0.51 \mathrm{ksi})$, i.e. $\tau_{z x r} / \sigma_{c f 0} \approx 1.75$ (or lower if restraint stresses due to shrinkage and hydration heat are considered), it is seen that in spite of the moderate fiber dosage used, with $\sigma_{c f 0}<f_{c t}$, the applied shear stresses $\tau_{z x}$ can increase after cracking if the crack spacing is small (near the minimum theoretical crack spacing) with $\tau_{z x u} / \tau_{z x r} \approx(1.82 \ldots 1.93) / 1.75=1.04 \ldots 1.10$, but a brittle failure at cracking would occur for the maximum theoretical crack spacing, with $\tau_{z x u} / \tau_{z x r} \approx(1.58 \ldots 1.63) / 1.75=0.90 \ldots 0.93$.

By examining the differences between $\lambda=1.0$ and $\lambda=0.5$ in Fig. 5 , it is evident that the crack spacing has a pronounced effect on the overall behavior, with differences in predicted ultimate loads ranging between $15 \ldots 20 \%$, even if the specimen is precracked, or if the cracking load is lower than estimated above. Hence, the inherent uncertainty in the spacing of cracks must be acknowledged when analyzing and designing FRC elements subjected to shear. However, even with larger crack spacings, a strain hardening behavior could be obtained using a higher conventional reinforcement ratio, as in the experiments discussed in the following section.

Figure 6 presents the results of a similar analysis for the FRC element without any conventional reinforcement, but subjected to imposed horizontal strains. The material parameters used in the analysis are indicated in the Figure. Horizontal strains were chosen to represent a typical prestressed concrete girder, with an initial prestress of $-5 \mathrm{MPa}(0.72 \mathrm{ksi})$ (corresponding to $\left.\varepsilon_{x}=-0.17 \cdot 10^{-3}\right)$ and 
401 longitudinal strains increasing only slightly until decompression of the tension chord $\left(\varepsilon_{x, T C}=0\right)$, 402 which is assumed to occur at $\tau_{z x}=1.5 \mathrm{MPa}(0.22 \mathrm{ksi})$. After decompression, longitudinal strains 403 grow faster until the tension chord yields at $\varepsilon_{x, T C}=2.0 \cdot 10^{-3}$ (e.g. reinforcement with $f_{y}=500 \mathrm{MPa}$ 404 (72.5 ksi) and moderate tension stiffening effect), assumed in the example to occur at $\tau_{z x}=4 \mathrm{MPa}$ 405 (0.58 ksi). As usual in design approaches for conventionally reinforced girders, longitudinal strains 406 at the mid-depth of the web are used as a reference point to predict the overall response ${ }^{19}$, i.e., 407 neglecting favorable strains of the compression chord, half the longitudinal strains of the tension 408 chord are imposed to the web, $\varepsilon_{x}=\varepsilon_{x, T C} / 2$. Assuming a maximum spacing of the cracks in the 409 tension chord triggering cracks in the web of $s_{r 0, T C}=400 \mathrm{~mm}(15.75 \mathrm{in}$.) and a principal compressive 410 stress direction at cracking of $\theta=30^{\circ}$ (a value lower than $45^{\circ}$ due to the effect of prestressing), a 411 maximum diagonal crack spacing of $s_{r f 0}=200 \mathrm{~mm}$ (7.87 in.) is obtained from Eq. (9). Since strains 412 are small before cracking of the concrete, which is expected to occur at $\varepsilon_{1}=\varepsilon_{c t}=f_{c t} / E_{c} \approx 10^{-4}$, the 413 cracking load $\tau_{z x r}$ is estimated as the shear stress $\tau_{z x r}$ acting at $\varepsilon_{x}=\varepsilon_{c t}$, corresponding to $414 \tau_{z x x} / \sigma_{c f 0} \approx 0.80$ here. Note that in a practical case, all the values assumed above would be determined 415 based on the actual applied prestressing (stress state in web before cracking), the moment-shear 416 interaction at the critical cross-section $M / V$, and the tension chord reinforcement layout, using a 417 sectional analysis.

418 The resulting behavior of the web is generally similar as in the uniaxially reinforced case. Failure is 419 caused by combined tensile softening of the fibers and compression softening of the concrete in all 420 cases. For linear elastic concrete, maximum loads amount to $\tau_{z x u} / \sigma_{c f 0}=2.34$ and $\tau_{z x u} / \sigma_{c f 0}=2.85$ 421 for $\lambda=1.0$ and $\lambda=0.5$, respectively. Corresponding values from the nonlinear analysis are $422 \tau_{z x u} / \sigma_{c f 0}=2.03$ and $\tau_{z x u} / \sigma_{c f 0}=2.21$. Hence, the assumed shear stress in the web at the onset of 423 yielding in the tension chord $\left(\tau_{z x}=4 \mathrm{MPa}(0.58 \mathrm{ksi})\right)$ is attained in all cases, though with little margin. 
424 Compared to the uniaxially reinforced case, the influence of crack spacing is similar, but somewhat 425 reduced in the nonlinear case (difference on the maximum load about $10 \%$ ). It can be seen that the 426 deformation capacity is larger, and the increase of shear stresses from cracking to maximum load is 427 substantially more pronounced for the case of where horizontal strains are imposed, with ratios $428 \tau_{z x u} / \tau_{z x r} \approx(2.03 \ldots 2.85) / 0.8=2.54 \ldots 3.56$, leading to a strain-hardening behavior even in the case of 429 large crack spacings (or if web cracking would occur at much higher loads than assumed here) in 430 spite of $\sigma_{c f 0}<f_{c t}$. This indicates that FRC webs without conventional reinforcement should exhibit 431 a much better performance than observed in tests on uniaxially reinforced panels, as long as the chords 432 do not yield; however, this presumption lacks experimental validation as no direct experimental 433 comparison currently exists.

434 Note that substantial compressive longitudinal stresses $\left(-\Delta \sigma_{x}\right.$, see Fig. $\left.4 c\right)$ are obtained due to the 435 longitudinal restraint caused by the imposed strains; these stresses assume the role of the longitudinal 436 reinforcement and must be resisted by the chords, in addition to chord forces induced by bending 437 (similar to the tension shift in girders with transverse reinforcement).

\section{COMPARISON WITH EXPERIMENTS}

439 In this section, predictions obtained from the simplified compression field analysis for uniaxially 440 reinforced FRC elements outlined above are validated against experimental results of tests carried out 441 by Susetyo et al. ${ }^{13,48}$. In these studies, eight uniaxially reinforced FRC panels $\left(\rho_{x}=3.31 \%\right.$, $\left.442 \varnothing_{x}=8.1 \mathrm{~mm}(0.32 \mathrm{in}),. f_{s}=552 \mathrm{MPa}(80.1 \mathrm{ksi})\right)$ and two orthogonally reinforced reference panels 443 measuring $890 \times 890 \times 70 \mathrm{~mm}(35 \times 35 \times 3.54$ in. $)$ thick were subjected to in-plane shear ${ }^{29}$. Two types of 444 concrete (normal and high strength) and three types of hooked-end fibers, with three different fiber 445 dosages were used. The fiber and matrix characteristics of the FRC panels are given in Table 1; it can 446 be seen that most specimens were provided with unpractically high fiber dosages $\left(\rho_{f}=1.5 \%\right)$, 447 reflecting the demands of codes mentioned in the introduction. 
448 For all predictions, the fiber stresses are strictly determined using Pfyl's model ${ }^{3}$ with $449 \tau_{b f}=2 f_{c t}=0.6 f_{c}^{2 / 3}$ (in MPa units) and $K_{f}=0.375$, without using any modifications or adaptations 450 based on material tests. Furthermore, the predicted crack spacing is determined from Eq. (8). Except 451 for the test specimens with the lowest fiber dosage, the lower bound $s_{r}=l_{f}$ in Eq. (8) governs 452 regardless of the considered value of $\lambda$. Therefore, in the following analyses, the crack spacing is 453 not varied (i.e. $\lambda=1$ is considered). For interest, crack spacings observed in the experiments for fiber 454 dosages of $1.00 \%$ and $1.50 \%$ match fairly well with $s_{r}=l_{f}$, as shown in Table 2 .

455 Figure 7 compares predictions carried out assuming (i) linear elastic behavior of the concrete in 456 compression as well as (ii) using the parabolic stress-strain relationship, (see Eq. (20)), to describe 457 the concrete in compression with the experimental results of three tests using normal strength concrete 458 with identical fibers, but with variable fiber dosages (i.e. specimens C1F1V1, C1F1V2, C1F1V3). 459 Both models shown in Fig. 7 consider linear elastic reinforcement behavior. While qualitatively the 460 agreement is satisfactory, the maximum loads and deformations are overestimated, particularly when 461 modelling the concrete as linear elastic, where failure is predicted by yielding of the reinforcement. 462 Note that specimen $\mathrm{C} 1 \mathrm{~F} 1 \mathrm{~V} 1$, with $\rho_{f}=0.5 \%$, remained uncracked during testing until just prior to 463 attaining maximum load, which explains the much stiffer observed behavior compared to the 464 prediction (which only models the post-cracking range). For nonlinear concrete accounting for 465 compression softening, failure is predicted by combined concrete crushing and fiber softening, but 466 deformations are still overestimated (albeit much less than by Reference ${ }^{48}$, in spite of their 467 customization of the tension softening characteristics of the FRC for each individual experiment, also 468 shown in Fig. 7). The most plausible explanation is the premature failure of the elements by sliding 469 along cracks generated in early load-stages, as observed in the tests ${ }^{13}$. Such failures, which are 470 difficult to distinguish from concrete crushing in experiments, are not reflected by rotating-crack 471 models like the CMM-Rf. These models implicitly assume that stresses can be transferred across 472 cracks formed at earlier load stages, whose direction may deviate significantly from the principal 
473 direction assumed at higher loads. In order to capture this effect, a model considering fixed, 474 interlocked cracks, such as the CMM-F, would be required. Another explanation could be that with 475 the fiber type used in the three experiments illustrated in Fig. 7, the fiber-fracture condition 476 represented by Eq. (12) is exceeded by roughly $25 \%$, such that the fibers with the longest embedded 477 length would fracture, instead of being pulled out as assumed in the predictions. Although the failure 478 surfaces of the panels were not reported by Susetyo, he noted that the panels did not contain any 479 fractured fibers in any of the dominant cracks $^{13}$. However, as fiber-fracture would only affect a small 480 portion of total amount of fibers bridging the crack it can only explain a small part of the 481 overestimation.

482 Figure 8 compares predictions carried out using the parabolic stress-strain relationship to describe the 483 concrete in compression using Eq. (20), with the experimental results of the remaining tests on FRC 484 panels documented in Reference ${ }^{48}$, all with identical fiber dosage $\left(\rho_{f}=1.5 \%\right)$ but different types of 485 hooked end fibers. Again, the agreement is satisfactory, particularly when compared to those in 486 Reference ${ }^{48}$ (shown in Fig. 8), however deformations and maximum loads are overestimated for both 487 the normal strength concrete panels, (refer to Fig. 8a), as well as the high strength concrete specimens 488 shown in Fig. 8b. Possible explanations for the normal strength concrete panels are the same as 489 discussed above. The more pronounced differences in the high strength concrete specimens could be 490 explained by the smoother crack faces in high strength concrete, caused by cracks passing through 491 the aggregates (rather than around them as is the case for normal strength concrete) ${ }^{49}$. Furthermore, 492 in Specimen C2F1V3-R, the fiber-fracture condition given by Eq. (12) is violated by roughly 70\%, 493 such that the majority of the fibers in this case would fracture rather than pull out as assumed in the 494 predictions; this could basically explain the overestimation of maximum load as well as deformations. 495 However, similar results are obtained for Specimen C2F2V3, where only about $75 \%$ of the tensile 496 strength of the fibers is reached according to Eq. (12). Hence, this explanation does not appear to be 497 conclusive. 
498 For interest, the predicted responses by Lee et al. ${ }^{50}$ using a finite element approach are also provided

499 in Figs. 7 and 8. In their model, Lee et al. considered crack slip, which essentially represents a fixed 500 crack model, however, disregarded the interaction between fiber stresses and aggregate interlock in 501 the transfer of shear across cracks. Despite the excellent correlation with the test data, it is 502 questionable whether the semi-empirical approach by Lee is extendable to other, more practical 503 dosages of SFRC.

\section{SUMMARY AND CONCLUSIONS}

505 This paper presents a simplified rotating crack model for the analysis and design of steel fiber 506 reinforced elements in shear (CMM-Rf) based on the Cracked Membrane Model with stress-free cracks (CMM-R) ${ }^{23,24}$. Simplified solution procedures of the CMM-Rf are developed for (i) uniaxially reinforced FRC elements in pure shear and (ii) FRC elements without conventional reinforcement, 509 but with imposed longitudinal strains. It is shown that the applied load can be increased after cracking 510 even when using practical, moderate fiber dosages. This is due to the fact that more fibers can be 511 activated by progressively rotating the principal compressive stress direction towards the direction of 512 the uniaxial reinforcement or imposed strain, respectively. A hardening response is thus obtained 513 until the point where due to the softening of the fibers, excessively flat inclinations of the principal 514 compressive stress direction are required to maintain equilibrium, resulting in failures by concrete 515 crushing particularly if compression softening is accounted for.

516 The model is compared with available test data and shows a satisfactory correlation. However, it is 517 revealed that rotating crack models are not capable of capturing failures which are governed by sliding 518 of cracks in elements with high fiber dosages. In order to cover such cases, it is proposed to extend 519 the general Cracked Membrane Model (CMM-F) $)^{23,24}$, which considers interlocked cracks with a fixed 520 orientation, to account for fiber reinforcement, in a future study. 
521 Finally, more experimental data is required in order to validate theoretical models, particularly with 522 practical and economical fiber dosages, as well as to investigate the behavior of FRC elements 523 without any conventional reinforcement, but with imposed longitudinal strains.

\section{REFERENCES}

1. Voo, Y. L., Foster, S. J., and Voo, C. C., "Ultrahigh-Performance Concrete Segmental Bridge Technology: Toward Sustainable Bridge Construction," Journal of Bridge Engineering, V. 20, No. 8, Aug. 2015, p. B5014001-1:12. doi: 10.1061/(ASCE)BE.1943-5592.0000704

2. Standards Australia. "AS 3600:2018. Australian Standard, Concrete Structures," 2018.

3. Pfyl, T. "Tragverhalten von Stahlfaserbeton.” PhD thesis, Institute of Structural Engineering, ETH Zurich, Switzerland, 2003.

4. Dancygier, A. N., and Berkover, E., "Cracking localization and reduced ductility in fiberreinforced concrete beams with low reinforcement ratios," Engineering Structures, V. 111, Mar. 2016, pp. 411-424. doi: 10.1016/j.engstruct.2015.11.046

5. Marti, P., Alvarez, M., Kaufmann, W., and Sigrist, V., "Tension Chord Model for Structural Concrete," Structural Engineering International, V. 8, No. 4, Nov. 1998, pp. 287-298. doi: $10.2749 / 101686698780488875$

6. Alvarez, M., and Marti, P. "Versuche zum Verbundverhalten von Bewehrungsstahl bei plastischen Verformungen," v. vol. 222, Birkhäuser, 1996, 135 pp.

7. Sigrist, V., and Marti, P. "Versuche zum Verformungsvermögen von Stahlbetonträgern,” v. vol. 202, Zurich, Switzerland, Institute of Structural Engineering, ETH Zurich, 1993, 90 pp.

8. Kaufmann, W., and Marti, P. "Versuche an Stahlbetonträgern unter Normal- und Querkraft," v. vol. 226, Basel, Switzerland, Birkhäuser, 1996.

9. Rupf, M. "Querkraftwiderstand von Stahlbeton- und Spannbetonträgern mittels Spannungsfeldern.” PhD thesis, École polytechnique fédérale de Lausanne (EPFL), Switzerland, 2014.

10. Angelakos, D., Bentz, E. C., and Collins, M. P., "Effect of Concrete Strength and Minimum Stirrups on Shear Strength of Large Members," ACI Structural Journal, V. 98, No. 3, May 2001, pp. 290-300. doi: 10.14359/10220 
11. Rahal, K. N., and Al-Shaleh, K. S., "Minimum Transverse Reinforcement in 65 Mpa Concrete Beams,” Structural Journal, V. 101, No. 6, Nov. 2004, pp. 872-878. doi: 10.14359/13463

12. Minelli, F. "Plain and fiber reinforced concrete beams under shear loading: structural behavior and design aspects." PhD thesis, Department of Civil Engineering, University of Brescia, Italy, 2005.

13. Susetyo, J. "Fibre Reinforcement for Shrinkage Crack Control in Prestressed, Precast Segmental Bridges.” PhD thesis, Department of Civil Engineering, University of Toronto, Canada, 2010.

14. Adebar, P., Mindess, S., St.-Pierre, D., and Olund, B., "Shear Tests of Fiber Concrete Beams without Stirrups," ACI Structural Journal, V. 94, No. 1, Jan. 1997, pp. 68-76. doi: 10.14359/462

15. Aoude, H., Belghiti, M., Cook, W. D., and Mitchell, D., "Response of Steel Fiber-Reinforced Concrete Beams with and without Stirrups," ACI Structural Journal, V. 109, No. 3, May 2012, pp. 359-368. doi: 10.14359/51683749

16. Standards Australia. "AS 5100.5:2017. Bridge design Part 5: Concrete," 2017.

17. Standards New Zealand "NZS 3101: Concrete structures standard Part 2 - commentary on the design of concrete structures,” Wellington, New Zealand, Standards New Zealand, 2006, 391 pp.

18. ACI Committee 318 "Building code requirements for structural concrete (ACI 318-08) and commentary," Farmington Hills, MI, American Concrete Institute, 2009.

19. International Federation for Structural Concrete. "fib Model Code for Concrete Structures 2010," Berlin, Germany, Wilhelm Ernst \& Sohn, 2013, 402 pp.

20. Bentz, E. C. "MC2010: Shear Strength of Beams and Implications of the New Approaches." Recent Developments on Shear and Punching Shear on RC and FRC Elements. Lausanne, Switzerland, International Federation for Structural Concrete, 2010. pp. 15-30.

21. Foster, S. J. "Design of FRC beams for shear using the VEM and the draft model code approach." Recent Developments on Shear and Punching Shear on RC and FRC Elements. Lausanne, Switzerland, International Federation for Structural Concrete, 2010. pp. 15-30.

22. European Committee for Standardization "Eurocode 2: Design of concrete structures - Part 1-1: General rules and rules for buildings," n.d.

23. Kaufmann, W. "Strength and deformations of structural concrete subjected to in-plane shear and normal forces." PhD thesis, Institute of Structural Engineering, ETH Zurich, Birkhäuser Verlag, Basel, Switzerland, 1998. 
24. Kaufmann, W., and Marti, P., "Structural Concrete: Cracked Membrane Model," Journal of Structural Engineering, ASCE, V. 124, Dec. 1998, pp. 1467-1475. doi: 10.1061/(ASCE)07339445(1998)124:12(1467)

25. Kupfer, H. “Erweiterung der Mörsch'schen Fachwerkanalogie mit Hilfe des Prinzips vom Minimum der Formänderungsenergie," CEB Bulletin d'information, No. 40, 1964, pp. 44-57.

26. Collins, M. P. “Towards a Rational Theory for RC Members in Shear," Journal of the Structural Division, ASCE, V. 104, No. 4, 1978, pp. 649-66.

27. Baumann, T. “Zur Frage der Netzbewehrung von Flächentragwerken,” Bauingenieur, V. 47, No. 10, 1972, pp. 367-77.

28. Mitchell, D., and Collins, M. P., "Diagonal Compression Field theory - A Rational Model For Structural Concrete in Pure Torsion,” ACI Journal, V. 71, No. 8, Aug. 1974, pp. 396-408. doi: $10.14359 / 7103$

29. Vecchio, F. J., and Collins, M. P., "The Modified Compression-Field Theory for Reinforced Concrete Elements subjected to Shear," ACI Journal, V. 83, No. 2, Mar. 1986, pp. 219-231. doi: $10.14359 / 10416$

30. Kaufmann, W., Mata-Falcón, J., and Beck, A. "Future directions for research on shear in structural concrete." fib Bulletin 85: Towards a rational understanding of shear in beams and slabs. 2018. pp. 323-38.

31. Hsu, T. T. C., "Softened Truss Model Theory for Shear and Torsion," ACI Structural Journal, V. 85, No. 6, Nov. 1988, pp. 624-635. doi: 10.14359/2740

32. Vecchio, F. J., "Disturbed Stress Field Model for Reinforced Concrete: Formulation,” Journal of Structural Engineering, ASCE, V. 126, No. 9, Sep. 2000, pp. 1070-1077. doi: 10.1061/(ASCE)0733-9445(2000)126:9(1070)

33. Foster, S. J., and Marti, P., “Cracked Membrane Model: Finite element implementation,” Journal of Structural Engineering, ASCE, V. 129, No. 9, 2003, pp. 1155-1163. doi: 10.1061/(ASCE)0733-9445(2003)129:9(1155)

34. Pimentel, M., and Figueiras, J. "Model for the analysis of structural concrete elements under plane stress conditions: FE implementation.” Computational modelling of Concrete Structures. Austria, CRC Press, 2010. pp. 391-400. 
35. Thoma, K., Roos, P., and Weber, M., "Finite-Elemente-Analyse von Stahlbetonbauteilen im ebenen Spannungszustand," Beton- und Stahlbetonbau, V. 109, No. 4, 2014, pp. 275-283. doi: doi.org/10.1002/best.201300087

36. Seelhofer, H. "Ebener Spannungszustand im Betonbau: Grundlagen und Anwendungen." PhD thesis, Institute of Structural Engineering, ETH Zurich, vdf Hochschulverlag, Switzerland, 2009.

37. Karagiannis, D., and Kaufmann, W. "Capacity Assessment of Concrete Box-Girder Bridge Webs Against the Combined Action of In-plane Shear and Transverse Bending." In: Hordijk, D. A., Luković, M., eds. High Tech Concrete: Where Technology and Engineering Meet. Maastricht, The Netherlands, Springer, 2018. pp. 693-700.

38. Thoma, K., "Finite element analysis of experimentally tested RC and PC beams using the cracked membrane model," Engineering Structures, V. 167, Jul. 2018, pp. 592-607. doi: 10.1016/j.engstruct.2018.04.010

39. Kaufmann, W., and Mata-Falcón, J. "Crack Widths in Structural Concrete Subjected to In-Plane Loading.” Workshop Proceedings No. 12. Oslo, Norway, Nordic Concrete Federation, 2017. pp. $21-5$.

40. Marti, P., Pfyl, T., Sigrist, V., and Ulaga, T., "Harmonized Test Procedures for Steel FiberReinforced Concrete," ACI Materials Journal, V. 96, No. 6, Nov. 1999, pp. 676-685. doi: $10.14359 / 794$

41. Amin, A., Foster, S. J., Gilbert, R. I., and Kaufmann, W., "Material characterisation of macro synthetic fibre reinforced concrete," Cement and Concrete Composites, V. 84, Nov. 2017, pp. 124-133. doi: 10.1016/j.cemconcomp.2017.08.018

42. Ng, T. S., Htut, T., and Foster, S. "Fracture of Steel Fibre Reinforced Concrete - The Unified Variable Engagement Model," Sydney, Australia, School of Civil and Environmental Engineering, The University of New South Wales, 2012, 107 pp.

43. Lee, S.-C., Cho, J.-Y., and Vecchio, F. J., "Diverse Embedment Model for Steel Fiber-Reinforced Concrete in Tension: Model Development," ACI Materials Journal, V. 108, No. 5, 2011, pp. 516-525. doi: 10.14359/51683261

44. Foster, S. J., "On Behavior of High-Strength Concrete Columns: Cover Spalling, Steel Fibers, and Ductility," ACI Structural Journal, V. 98, No. 4, Jul. 2001, pp. 583-589. doi: $10.14359 / 10301$ 
638 45. Amin, A., and Foster, S. J. "Shear strength of steel fibre reinforced concrete beams with stirrups," 639 Engineering Structures, V. 111, 2016, pp. 323-32. doi: 10.1016/j.engstruct.2015.12.026

640 46. Deluce, J. R. "Cracking Behaviour of Steel Fibre Reinforced Concrete Containing Conventional 641 Steel Reinforcement." MSc dissertation, Department of Civil Engineering, University of 642 Toronto, 2011.

643 47. Amin, A. "Post Cracking Behaviour of Steel Fibre Reinforced Concrete: From Material to 644 Structure," PhD Thesis, School of Civil and Environmental Engineering, The University of New $645 \quad$ South Wales, 2015.

646 45. Susetyo, J., Gauvreau, P., and Vecchio, F. J., "Steel Fiber-Reinforced Concrete Panels in Shear: 647 648 Analysis and Modeling,” ACI Structural Journal, V. 110, No. 2, Mar. 2013, pp. 285-296. doi: $10.14359 / 51684408$

49. Walraven, J. C. "Fundamental Analysis of Aggregate Interlock," Journal of the Structural Division, ASCE, V. 107, No. 11, 1981, pp. 2245-70.

50. Lee, S.-C., Cho, J.-Y., and Vecchio, F. J. “Analysis of Steel Fiber-Reinforced Concrete Elements 653 
655 This Appendix contains additional information that were not provided in the main body of the paper

656 for the sake of brevity.

\section{Notation}

$658 \quad d_{f}=$ diameter of fiber

$659 \quad E_{c}=$ elastic modulus of concrete

$660 \quad E_{f}=\quad$ elastic modulus of fibers

$661 E_{s}=\quad$ elastic modulus of steel reinforcement

$662 E_{s h}=$ hardening modulus of steel reinforcement

$663 K_{f}=$ fiber orientation factor

$664 f_{c}=$ compressive strength of concrete matrix

$665 f_{c t}=$ tensile strength of concrete matrix

$666 f_{s}=$ yield strength of longitudinal reinforcement

$667 f_{t}=\quad$ ultimate strength of longitudinal reinforcement

$668 f_{t f}=\quad$ ultimate strength of fiber reinforcement

$669 l_{f}=$ length of fiber

$670 l_{f b}=$ embedded length of fiber

$671 n=$ modular ratio

$672 s_{r}=$ diagonal crack spacing without fibres

$673 s_{r 0}=$ maximum diagonal crack spacing without fibres

$674 s_{r f}=$ diagonal crack spacing for SFRC members

$675 s_{r f 0}=$ maximum diagonal crack spacing for SFRC members

$676 u=$ orthogonal crack opening

$677 V_{R}=$ total shear force

$678 V_{R c}=$ ultimate shear force carried by concrete

$679 V_{R f}=$ ultimate shear force carried by fibers

$680 V_{R s}=$ ultimate shear force carried by transverse reinforcement

$681 w_{r}=\quad$ crack opening

$682 \varepsilon=$ strain

$683 \quad \varepsilon_{c 0}=\quad$ strain of concrete corresponding to the peak compressive stress

$684 \varepsilon_{s u}=$ ultimate tensile strain of longitudinal reinforcement 


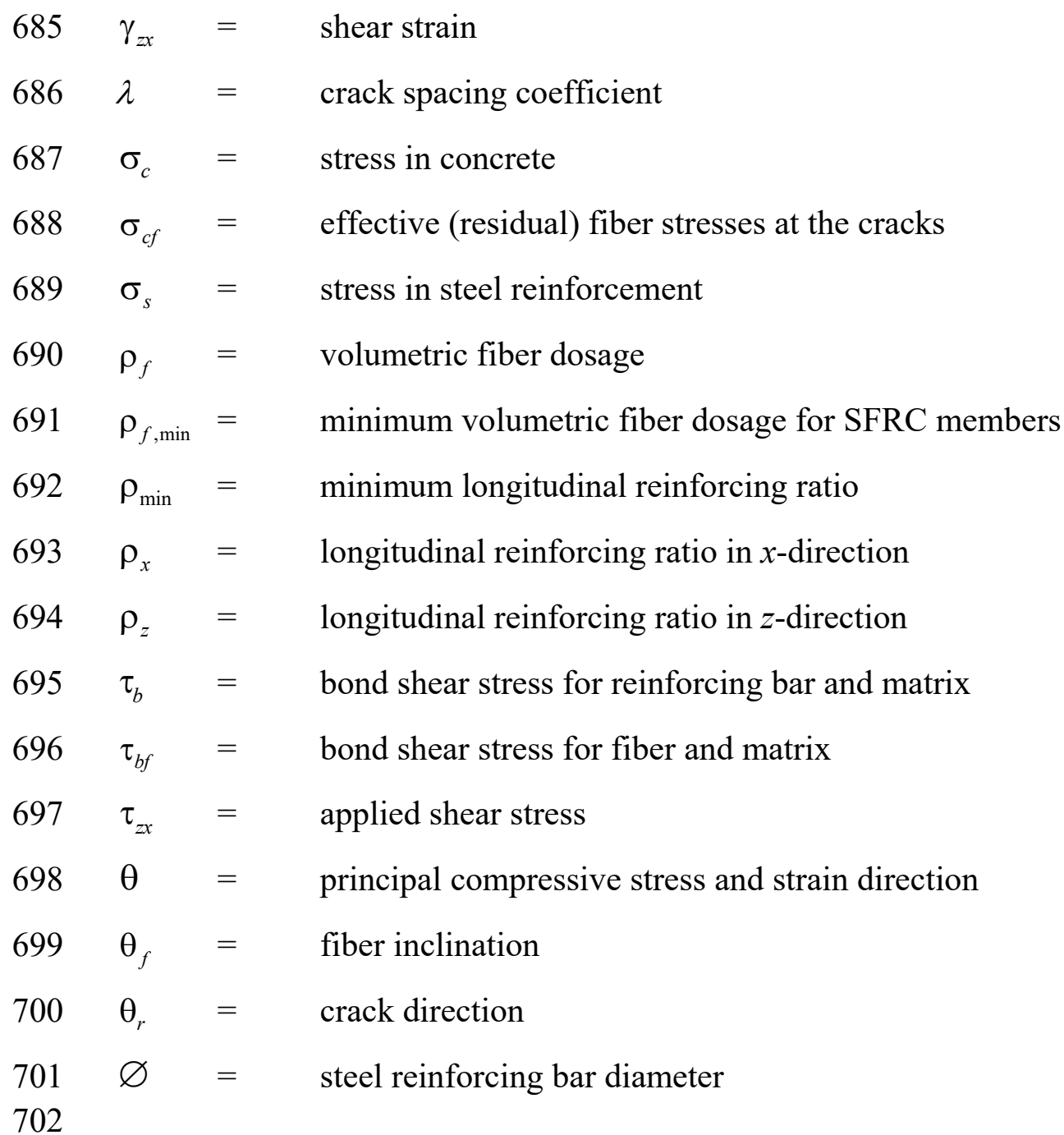

\section{Calculation of fiber orientation factor}

704 Assuming that all possible fiber orientations have an equal probability of occurrence (either in 2D or $7053 \mathrm{D}$, or, in few cases, in-between), the fiber orientation factor, $K_{f}$, is obtained by integrating all 706 possible fiber orientations, observing that the amount of fibers with an inclination $\theta_{f}$ crossing a crack 707 plane of unit surface amounts to $\cos \theta_{f}$, see Fig. A.1a. Discounting the fibers whose inclination 708 exceeds $\left|\theta_{f}\right|>\theta_{\text {eff }}$, one obtains

$$
K_{f}=\frac{1}{\pi} \int_{-\theta_{e f f}}^{\theta_{e f f}} \cos \theta_{f} d \theta_{f}=\frac{2}{\pi} \sin \theta_{\text {eff }} \quad\left(\theta_{\text {eff }}=\frac{\pi}{2}: K_{f}=\frac{2}{\pi} ; \quad \theta_{\text {eff }}=\frac{\pi}{3}: K_{f}=\frac{\sqrt{3}}{\pi}\right)
$$

710 for a $2 \mathrm{D}$ fiber distribution and 


$$
K_{f}=\frac{1}{2 \pi} \int_{-\pi}^{\pi} \int_{0}^{\theta_{e f f}} \cos \theta_{f} d A=\frac{1}{2} \sin ^{2} \theta_{\text {eff }} \quad\left(\theta_{\text {eff }}=\frac{\pi}{2}: K_{f}=\frac{1}{2} ; \quad \theta_{\text {eff }}=\frac{\pi}{3}: K_{f}=\frac{3}{8}\right)
$$

712 for a 3D fiber distribution, where $d A=\sin \theta_{f} \cdot d \theta_{f} \cdot d \varphi$ in spherical coordinates has been used.

713 Note that Eqs. (A.1) and (A.2) can be interpreted as the projection of the surface $S$ defined by the 714 fiber end loci of all effective fibers to the crack plane (a semi-circle and a semi-sphere for the 2D and $7153 \mathrm{D}$ case), divided by the surface $S$, see Fig. A.1b and c, respectively.

(a)

(b)

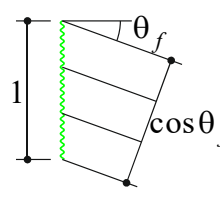

716

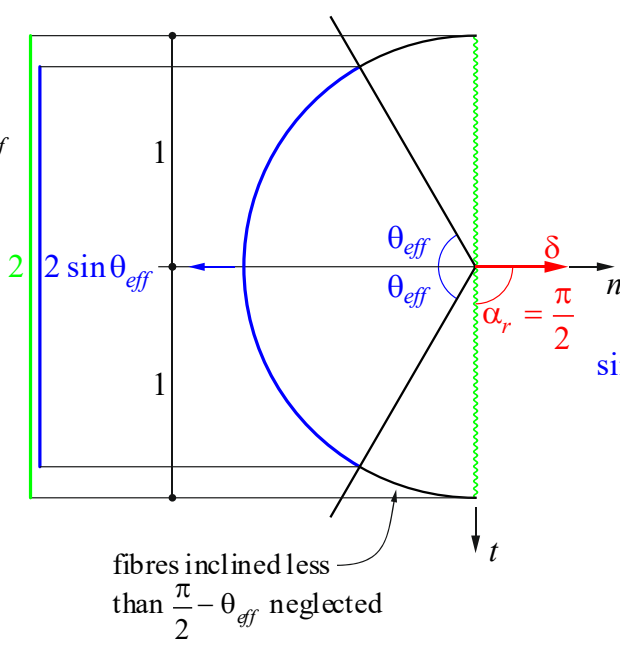

(c)

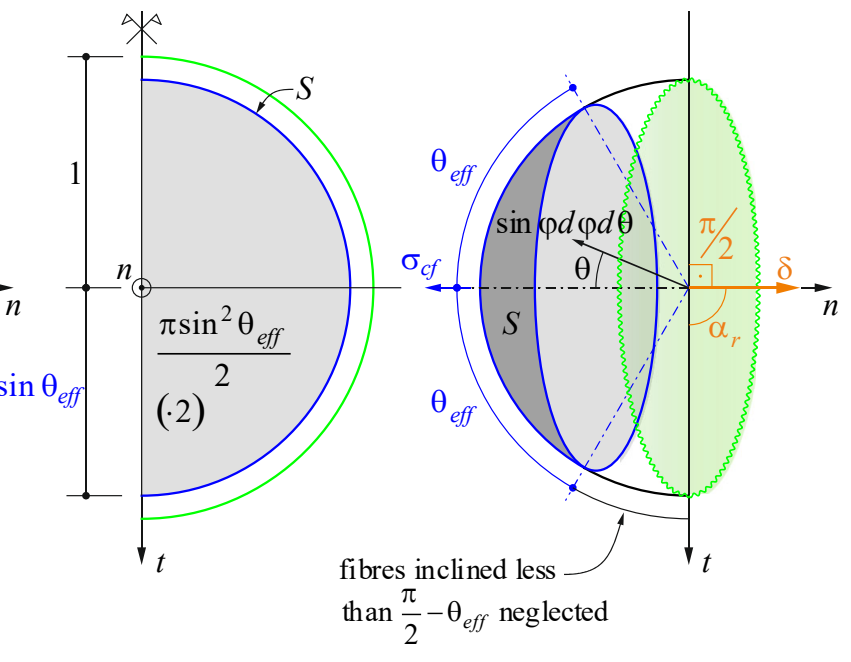

717 Fig. A.1-Fiber orientation factor for orthogonal crack opening: (a) notation, (b) 2D and (c) 3D fiber 718 distribution, respectively, neglecting fibers oriented close to the crack plane. 
List of Tables:

722 Table 1 - Fiber and matrix characteristics of tests by Susetyo et al. ${ }^{48}$ (specimen designation:

$723 \mathrm{C}=$ concrete type $1-2 ; \mathrm{F}=$ fiber type $1-3 ; \mathrm{V}=$ fiber dosage $1-3 ; \mathrm{R}=$ repeated due to experimental 724 problems in initial test).

725 Table 2 - Comparison of predicted crack spacing, $s_{r f}$, and observed average crack spacing, $s_{r, \text { exp }}$, for 726 tests by Susetyo et al. ${ }^{48}$.

\section{List of Figures:}

729 Fig. 1 - Compression field approaches: (a) notation; (b) average surface strains; (c) concrete stresses 730 at cracks (zero tensile stresses in the concrete); (d) concrete stresses (including tensile stresses in the 731 concrete).

732 Fig. 2 - Cracked membrane element with one set of parallel cracks of fixed direction: (a) element 733 with applied stresses; (b) stresses at the crack; (c) crack kinematics.

734 Fig. 3 - Fiber engagement at orthogonal crack openings: (a) Single fiber pullout; (b) FRC activation 735 and pullout phases.

736 Fig. 4 - Compression field approach for FRC element with $\rho_{z}=0, \sigma_{z}=0$ : (a) notation; (b) average 737 surface strains; (c) stresses at cracks.

738 Fig. 5 - Uniaxially reinforced FRC element in pure shear, comparison of simplified linear (dashed 739 lines) and nonlinear (solid lines) compression field analysis with increasing shear $\tau_{z x}$ for maximum 740 and minimum theoretical crack spacing: (a) Normalized fiber stresses $\sigma_{c f} / \sigma_{c f 0}$ and concrete 741 compressive stresses $-\sigma_{c 3} / f_{\text {cred }},-\sigma_{c 3} / f_{c}$; (b) principal direction $\cot \theta[-]$, crack opening $\mathrm{u}[\mathrm{mm}]$, 742 longitudinal strains $\varepsilon_{x}[-]$, and shear strains $\gamma_{z x}[-]$ (vertical dotted lines indicate yielding of a 500 743 MPa yield strength reinforcement). 
744 Fig. 6 - FRC element without conventional reinforcement, but imposed horizontal strains, 745 comparison of simplified linear (dashed lines) and nonlinear (solid lines) compression field analysis 746 with increasing shear $\tau_{z x}$ for maximum and minimum theoretical crack spacing: (a) Normalized fiber 747 stresses $\sigma_{c f} / \sigma_{c f 0}$ and concrete compressive stresses $-\sigma_{c 3} / f_{c r e d},-\sigma_{c 3} / f_{c} ;$ (b) principal direction $748 \cot \theta[-]$, crack opening $\mathrm{u}[\mathrm{mm}]$, longitudinal strains $\varepsilon_{x}[-]$, and shear strains $\gamma_{z x}$.

749 Fig. 7 - Comparison of predictions by the simplified compression field with tests by Susetyo et al. ${ }^{48}$ 750 for nonlinear concrete, accounting for compression softening (solid lines) and linear elastic concrete 751 (dashed lines). For comparison, predictions given in in References ${ }^{48,50}$ are also indicated.

752 Fig. 8 - Comparison of predictions by the simplified compression field with tests by Susetyo et al. ${ }^{48}$ 753 for nonlinear concrete, accounting for compression softening: (a) normal strength concrete; (b) high 754 strength concrete. For comparison, predictions given in References ${ }^{48,50}$ are also indicated. 
756 Table 1 - Fiber and matrix characteristics of tests by Susetyo et al. ${ }^{48}$ (specimen designation: $757 C=$ concrete type 1-2; F=fiber type 1-3; V=fiber dosage 1-3; R=repeated due to experimental 758 problems in initial test).

\begin{tabular}{|c|c|c|c|c|c|c|}
\hline Specimen & $\begin{array}{c}f_{c} \\
{[\mathrm{MPa}]([\mathrm{ksi}])}\end{array}$ & $\begin{array}{c}-\varepsilon_{c 0} \\
\left(\mathrm{x} 10^{-3}\right)\end{array}$ & $\begin{array}{c}\rho_{f} \\
(\%)\end{array}$ & $\begin{array}{c}d_{f} \\
{[\mathrm{~mm}]([\mathrm{in} .])}\end{array}$ & $\begin{array}{c}l_{f} \\
{[\mathrm{~mm}][(\mathrm{in} .)]}\end{array}$ & $\begin{array}{c}f_{t f} \\
{[\mathrm{MPa}][(\mathrm{ksi})]}\end{array}$ \\
\hline C1F1V1 & $51.4(7.45)$ & 2.15 & 0.50 & $0.62(0.024)$ & $50(1.97)$ & $1050(152.3)$ \\
\hline C1F1V2 & $53.4(7.74)$ & 2.67 & 1.00 & $0.62(0.024)$ & $50(1.97)$ & $1050(152.3)$ \\
\hline C1F1V3 & $49.7(7.21)$ & 2.50 & 1.50 & $0.62(0.024)$ & $50(1.97)$ & $1050(152.3)$ \\
\hline C1F2V3 & $59.7(8.66)$ & 3.27 & 1.50 & $0.38(0.015)$ & $30(1.18)$ & $2300(333.6)$ \\
\hline C1F3V3 & $45.5(6.60)$ & 2.34 & 1.50 & $0.55(0.022)$ & $35(1.38)$ & $1100(159.5)$ \\
\hline C2F1V3-R & $78.8(11.43)$ & 2.78 & 1.50 & $0.62(0.024)$ & $50(1.97)$ & $1050(152.3)$ \\
\hline C2F2V3 & $76.5(11.10)$ & 2.22 & 1.50 & $0.38(0.015)$ & $30(1.18)$ & $2300(333.6)$ \\
\hline C2F3V3 & $62.0(8.99)$ & 2.03 & 1.50 & $0.55(0.022)$ & $35(1.38)$ & $1100(159.5)$ \\
\hline
\end{tabular}

760 Table 2 - Comparison of predicted crack spacing, $s_{r f}$, and observed average crack spacing, $s_{r, \text { exp }}$, for 761 tests by Susetyo et al. ${ }^{48}$.

\begin{tabular}{|c|c|c|c|}
\hline Specimen & $\begin{array}{c}s_{r, \exp } \\
{[\mathrm{mm}]([\mathrm{in} .])}\end{array}$ & $\begin{array}{c}s_{r f}(\lambda=0.5)-\text { Eq. }(8) \\
{[\mathrm{mm}]([\mathrm{in} .])}\end{array}$ & $\begin{array}{c}s_{r f}(\lambda=1.0)-\text { Eq. (8) } \\
{[\mathrm{mm}]([\mathrm{in} .])}\end{array}$ \\
\hline C1F1V1 & $114(4.49)$ & $146(5.75)$ & $73(2.87)$ \\
\hline C1F1V2 & $55(2.17)$ & $50(1.97)$ & $50(1.97)$ \\
\hline C1F1V3 & $57(2.24)$ & $50(1.97)$ & $50(1.97)$ \\
\hline C1F2V3 & $38(1.50)$ & $30(1.18)$ & $30(1.18)$ \\
\hline C1F3V3 & $57(2.24)$ & $35(1.38)$ & $35(1.38)$ \\
\hline C2F1V3-R & $36(1.42)$ & $50(1.97)$ & $50(1.97)$ \\
\hline C2F2V3 & $47(1.85)$ & $30(1.18)$ & $30(1.18)$ \\
\hline C2F3V3 & $41(1.61)$ & $35(1.38)$ & $35(1.38)$ \\
\hline
\end{tabular}

762 


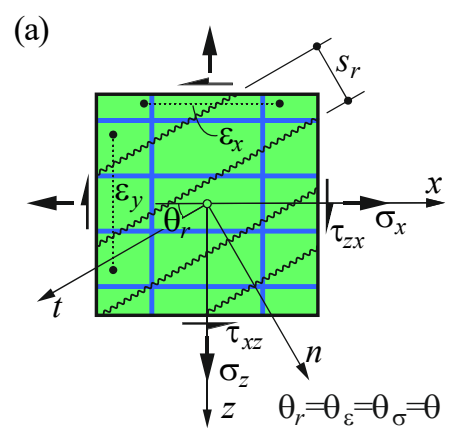

(b) $\quad \gamma / 2$

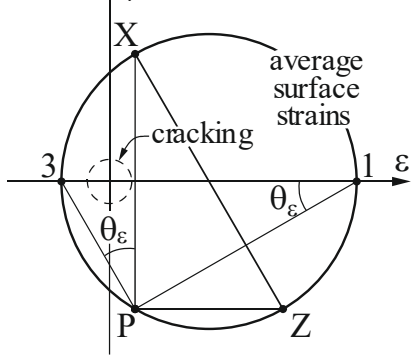

(c)

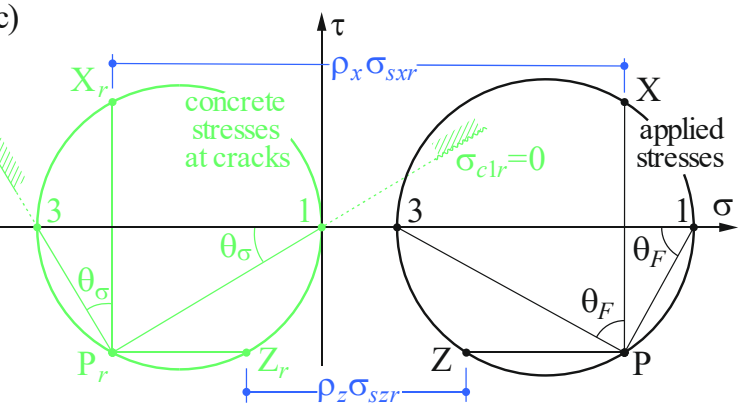

(d)

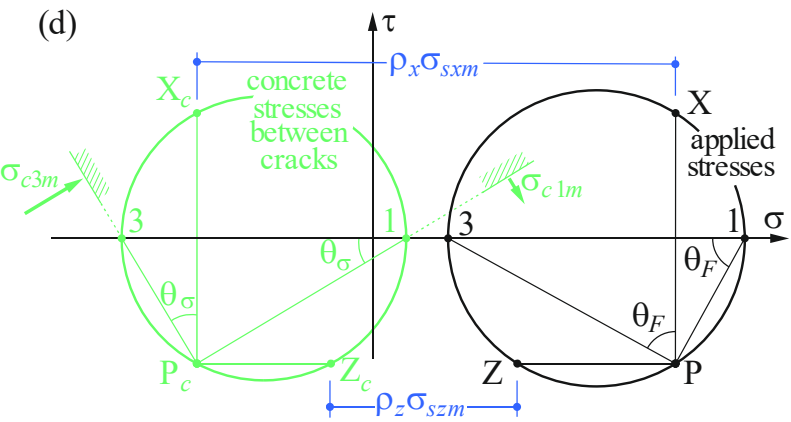

764

765

766

767

768

Fig. 1 - Compression field approaches: (a) notation; (b) average surface strains; (c) concrete stresses at cracks (zero tensile stresses in the concrete); (d) concrete stresses (including tensile stresses in the concrete).

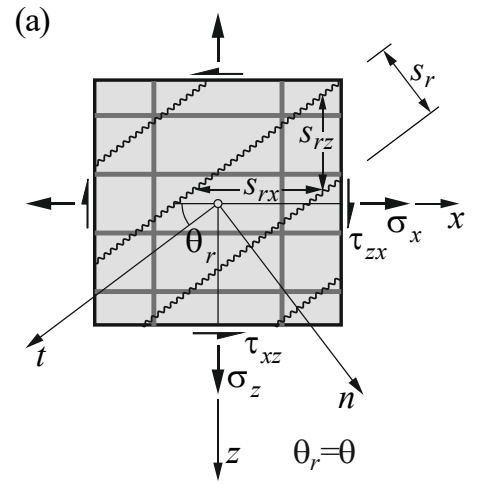

(a) (b)
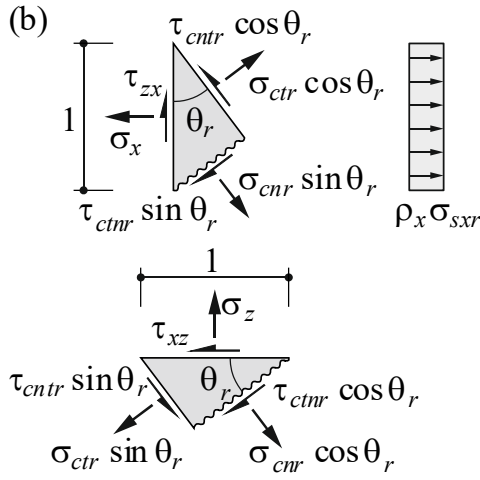

†. म. $\rho_{z} \sigma_{s z r}$ (c)

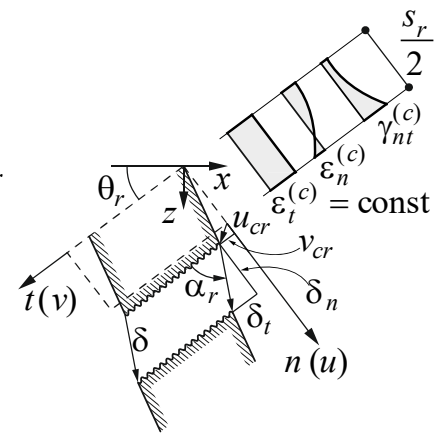

770 Fig. 2 - Cracked membrane element with one set of parallel cracks of fixed direction: (a) element 771 with applied stresses; (b) stresses at the crack; (c) crack kinematics. 
(a)

773

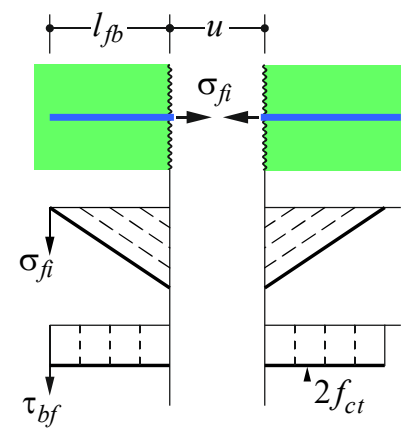

(b)

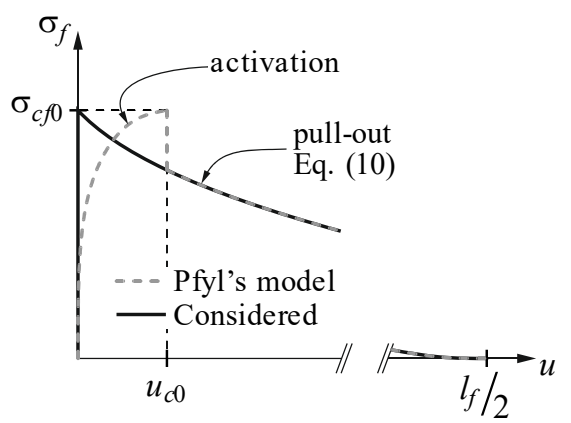

774 Fig. 3 - Fiber engagement at orthogonal crack openings: (a) Single fiber pullout; (b) FRC activation 775 and pullout phases.

776

(a)

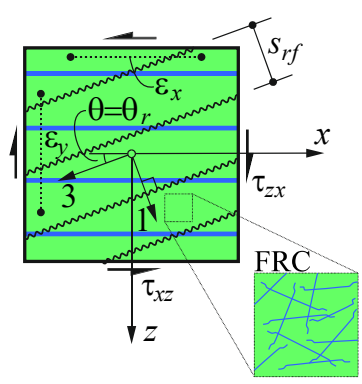

(b)

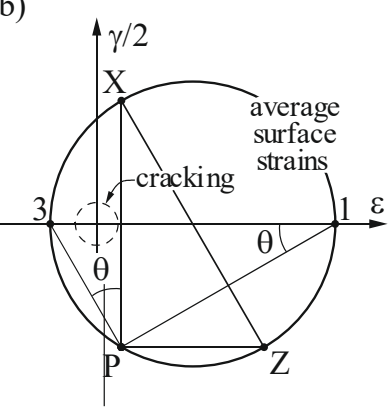

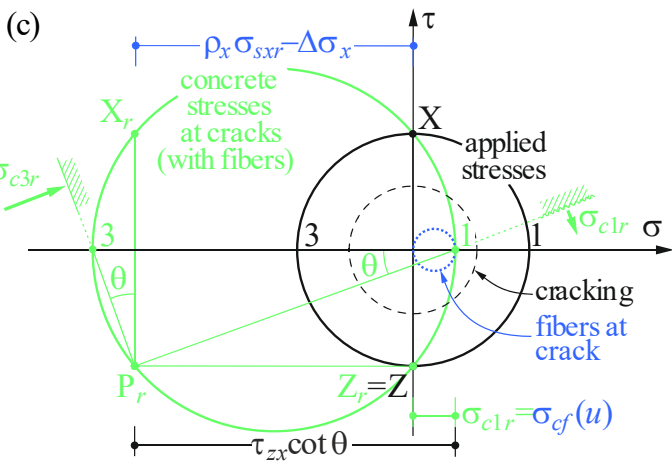

(c)

778 Fig. 4-Compression field approach for FRC element with $\rho_{z}=0, \sigma_{z}=0:$ (a) notation; (b) average 779 surface strains; (c) stresses at cracks. 


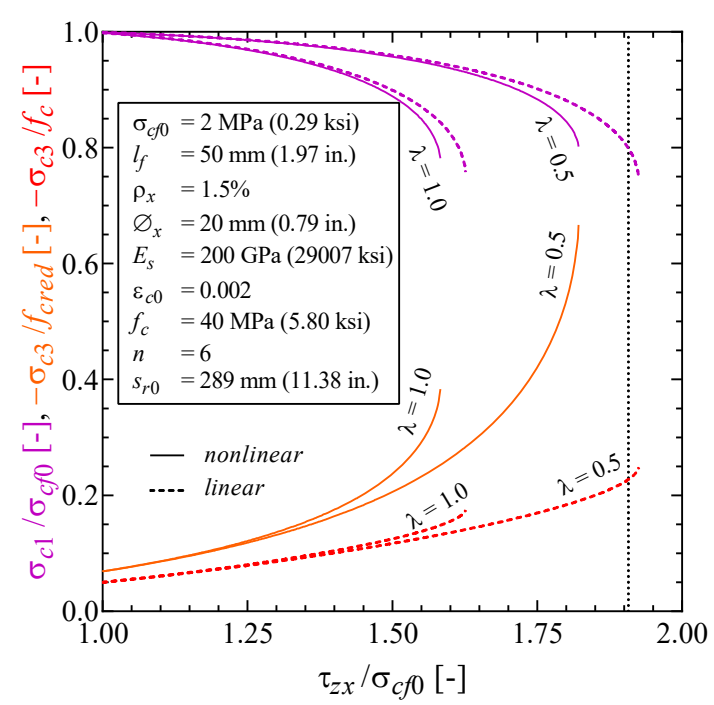

(a)

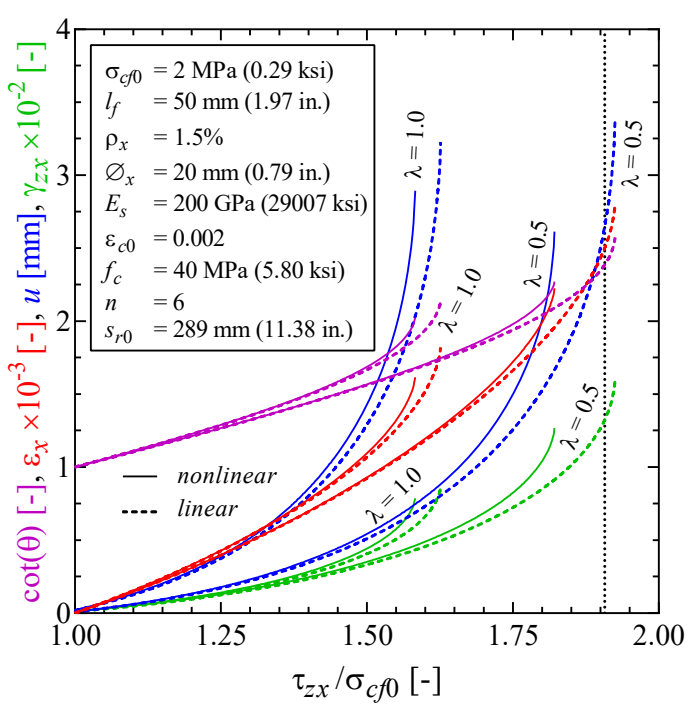

(b)

781 Fig. 5 - Uniaxially reinforced FRC element in pure shear, comparison of simplified linear (dashed 782 lines) and nonlinear (solid lines) compression field analysis with increasing shear $\tau_{z x}$ for maximum 783 and minimum theoretical crack spacing: (a) Normalized fiber stresses $\sigma_{c f} / \sigma_{c f 0}$ and concrete 784 compressive stresses $-\sigma_{c 3} / f_{\text {cred }},-\sigma_{c 3} / f_{c}$; (b) principal direction $\cot \theta$ [-], crack opening $u$ [mm], 785 longitudinal strains $\varepsilon_{x}[-]$, and shear strains $\gamma_{z x}[-]$ (vertical dotted lines indicate yielding of a 500 MPa yield strength reinforcement).

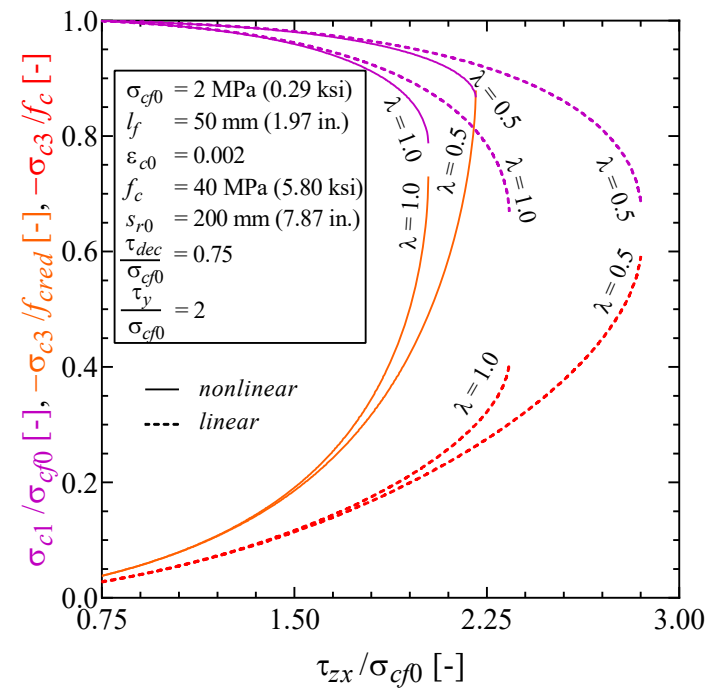

(a)

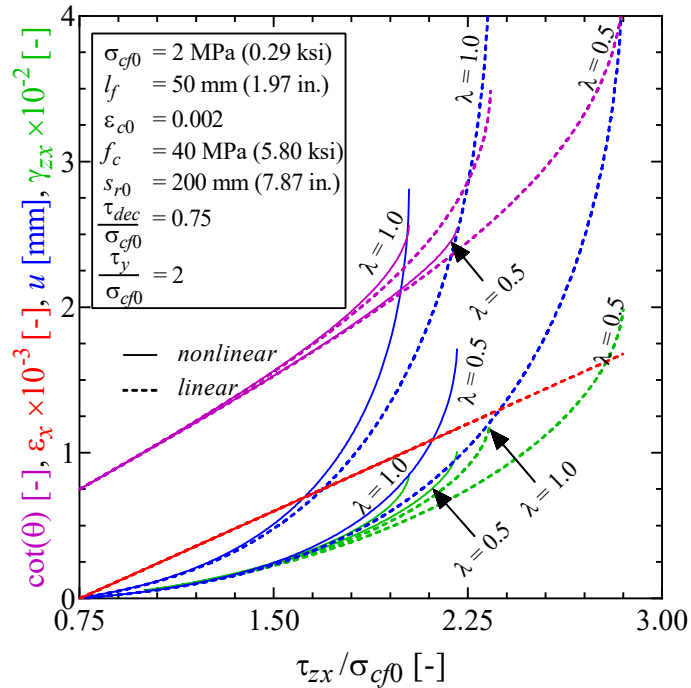

(b)

Fig. 6 - FRC element without conventional reinforcement, but imposed horizontal strains, comparison of simplified linear (dashed lines) and nonlinear (solid lines) compression field analysis with increasing shear $\tau_{z x}$ for maximum and minimum theoretical crack spacing: (a) Normalized fiber stresses $\sigma_{c f} / \sigma_{c f 0}$ and concrete compressive stresses $-\sigma_{c 3} / f_{c r e d},-\sigma_{c 3} / f_{c}$; (b) principal direction $\cot \theta[-]$, crack opening $u[\mathrm{~mm}]$, longitudinal strains $\varepsilon_{x}[-]$, and shear strains $\gamma_{z x}$. 


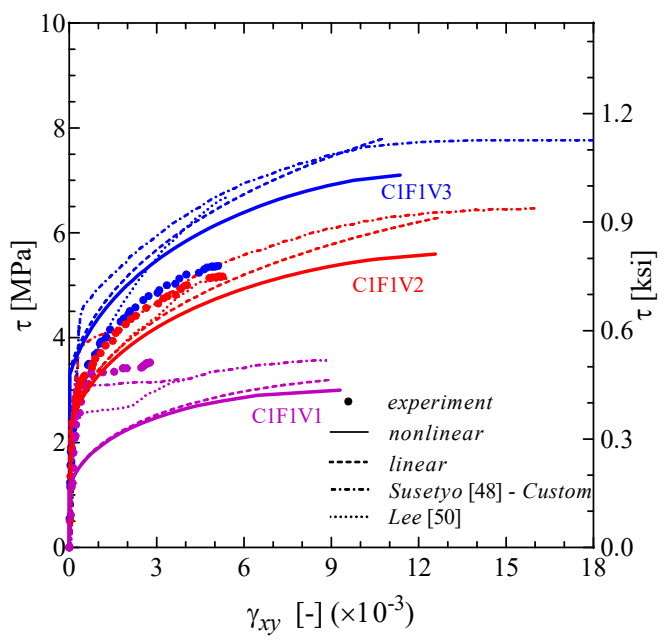

793 Fig. 7 - Comparison of predictions by the simplified compression field with tests by Susetyo et al. ${ }^{48}$ 794 for nonlinear concrete, accounting for compression softening (solid lines) and linear elastic concrete 795 (dashed lines). For comparison, predictions given in in References ${ }^{48,50}$ are also indicated.

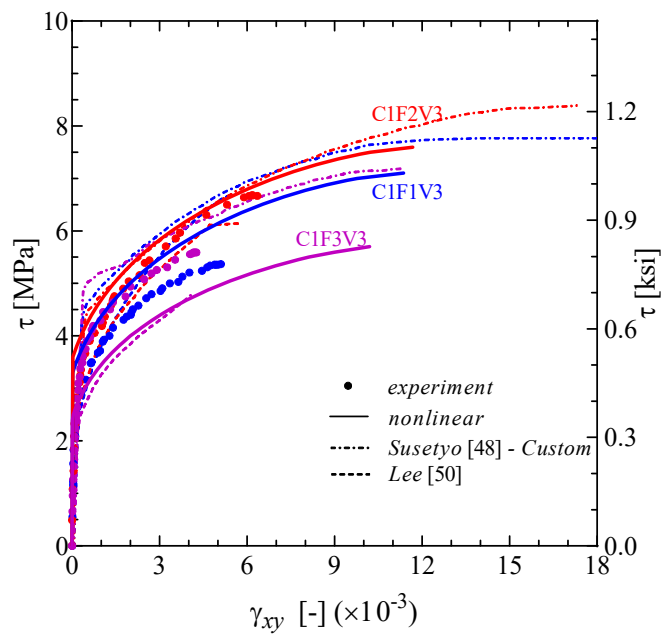

(a)

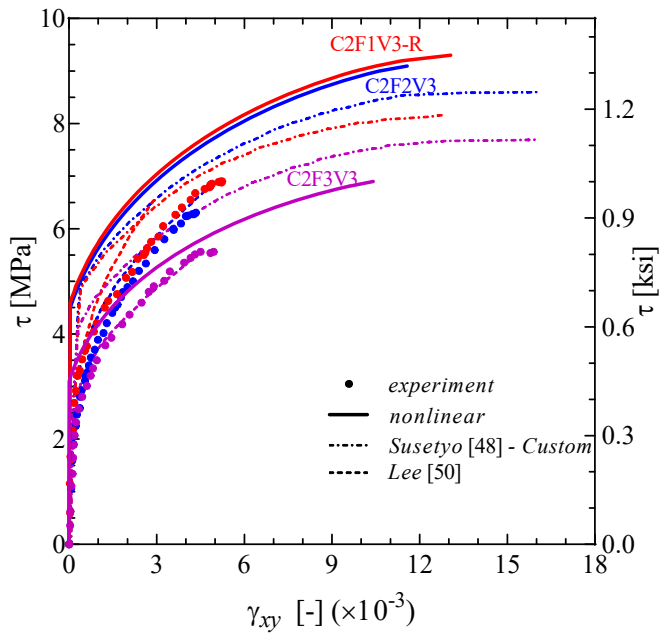

(b)

796 Fig. 8 - Comparison of predictions by the simplified compression field with tests by Susetyo et al. ${ }^{48}$ 797 for nonlinear concrete, accounting for compression softening: (a) normal strength concrete; (b) high 798 strength concrete. For comparison, predictions given in References ${ }^{48,50}$ are also indicated. 